\title{
Características térmicas de materiais de mudança de fase adequados para edificações brasileiras
}

\author{
Thermal characteristics of phase change materials \\ suitable for Brazilian buildings
}

\section{Adriana Camargo de Brito Maria Akutsu \\ Elisa Morande Salles Guilherme Molnar Castro}

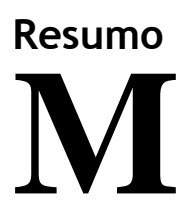

ateriais de mudança de fase - Phase Change Materials (PCMs) apresentam uma capacidade de armazenamento térmico substancialmente maior que os materiais convencionais. PCMs aplicados na envoltória de edificações contribuem para o aumento da inércia térmica de ambientes, proporcionando recintos com melhor desempenho térmico, dependendo do clima. Atualmente, há PCMs utilizados em edificações do hemisfério norte, especialmente, havendo poucas informações sobre seu uso em edificações em países tropicais. Neste artigo são apresentadas as características térmicas essenciais que estes materiais precisam ter, quanto à sua capacidade de armazenamento térmico latente e ponto de fusão, para contribuir para a melhoria do desempenho térmico de edificações brasileiras. Foram efetuadas simulações da resposta térmica de edificações com o programa EnergyPlus ${ }^{\circledR}$ em duas etapas: a) reproduziu-se o comportamento térmico de um modelo existente com PCMs verificando-se a similaridade entre dados medidos e simulados para indicar a confiabilidade das simulações; b) foram feitas simulações de modelos com fechamentos leves e pesados, com e sem PCMs em cidades brasileiras, variando-se as características do PCM original, quanto à capacidade de armazenamento térmico latente e o ponto de fusão. Os resultados apontam os intervalos dessas grandezas que proporcionaram melhor desempenho térmico dos recintos em função dos fechamentos e do clima do local, sendo uma referência inicial para o desenvolvimento de produtos mais adequados ao clima de regiões brasileiras.

Palavras-chaves: Mudança de fase. Calor latente. Inércia térmica. Desempenho térmico.

Adriana Camargo de Brito Instituto de Pesquisas Tecnológicas do Estado de São Paulo São Paulo - SP - Brasil

Maria Akutsu Instituto de Pesquisas Tecnológicas do Estado de São Paulo São Paulo - SP - Brasil

Elisa Morande Salles Instituto de Pesquisas Tecnológicas do Estado de São Paulo São Paulo - SP - Brasil

Guilherme Molnar Castro Universidade de São Paulo São Paulo - SP - Brasil

Recebido em 26/03/16 Aceito em 30/05/16

\section{Abstract}

Phase Change Materials (PCMs) have significantly higher thermal capacity than traditional materials. PCMs increase the thermal inertia of buildings and improve their thermal performance depending on the climate conditions. PCMs are generally used in buildings exposed to the Northern Hemisphere's climate conditions; however, there is very little information about the effect of these materials in buildings located in tropical areas. This paper presents the essential thermal characteristics that these materials require (latent heat and melting point) to be able to contribute to improve the thermal performance of Brazilian buildings. Simulations of the thermal response of buildings with and without PCMs were carried out. The first stage aimed to reproduce the thermal behaviour of a real prototype - with PCMs available in the market in order to validate the simulations. The second stage included parametric simulations of the thermal response of a prototype with hypothetical PCMs. The characteristics of these hypothetical materials were obtained from variations of the original ones. The results show the values of the latent heat and melting point most appropriate to Brazilian buildings.

Keywords: PCM. Latent heat. Thermal inertia. Thermal performance.

BRITO, A. C. de; AKUTSU, M.; SALLES, E. M.; CASTRO, G. M. Características térmicas de materiais de mudança de fase 125 adequados para edificações brasileiras. Ambiente Construído, Porto Alegre, v. 17, n. 1, p. 125-145, jan./mar. 2017. ISSN 1678-8621 Associação Nacional de Tecnologia do Ambiente Construído.

http://dx.doi.org/10.1590/s1678-86212017000100128 


\section{Introdução}

Os materiais de mudança de fase, do termo em inglês Phase Change Materials ou PCMs, são desenvolvidos para atuarem como "armazenadores" de energia na forma de calor. Esses materiais sofrem mudanças cíclicas de estado quando expostos a determinadas condições ambientais, absorvendo ou dissipando grande quantidade de calor, o que lhes proporciona uma capacidade de armazenamento térmico por unidade de volume significativamente maior do que ocorre nos materiais convencionais (BAETENS; JELLE; GUSTAVSEN, 2010; MEHLING; CABEZA, 2008).

Os materiais convencionais dissipam ou absorvem calor em função das diferenças entre os valores das temperaturas dos materiais e do meio ao qual estão expostos (calor sensível). Os PCMs têm comportamento térmico similar aos materiais convencionais nos intervalos entre as suas mudanças de fase. Nos momentos em que ocorrem tais mudanças, eles absorvem ou dissipam quantidades mais significativas de calor (latente), mantendo sua temperatura constante. Em decorrência desse fenômeno, uma fina camada de um produto com PCMs pode ter uma capacidade de armazenamento térmico maior que uma camada mais espessa de um material convencional.

As mudanças de fase dos PCMs podem ocorrer entre estados, do sólido para o líquido e vice-versa e do líquido para o gasoso e vice-versa. Atualmente, é mais comum o uso de materiais que transitam da fase sólida para a fase líquida e seu inverso. Embora materiais com tais características apresentem capacidade de armazenamento térmico latente inferior aos demais, eles têm como vantagem a ocorrência de menor variação volumétrica durante as mudanças de estado, o que facilita a sua contenção (MEHLING; CABEZA, 2008; SHARMA et al., 2009). Os PCMs são utilizados em produtos variados, tais como coletores solares, satélites, equipamentos eletrônicos, produtos têxteis e em componentes construtivos de edifícios.

Em componentes construtivos, os PCMs funcionam como elementos passivos para condicionamento ambiental. Normalmente, são aplicados em fechamentos leves, que em sua forma original possuem baixa capacidade de armazenamento térmico latente, com o intuito de aumentar a inércia térmica dos ambientes. Nessas situações, dependendo do clima do local e das características dos PCMs, esses materiais podem contribuir para a obtenção de condições térmicas mais adequadas ao conforto do usuário, o que reduz ou elimina a necessidade do uso de equipamentos de climatização.

Dentre todos os requisitos que os PCMs devem ter para serem utilizados em produtos, como alta condutividade térmica, estabilidade físico-química, manutenção dos ciclos e a segurança do usuário (GUYER, 1999; FARID et al., 2004; MEHLING; CABEZA, 2008; SHARMA et al., 2009), é fundamental que $\mathrm{O}$ material tenha valores adequados da sua capacidade de armazenamento térmico latente e dos pontos de fusão e solidificação. Estes últimos são fatores determinantes do seu desempenho térmico quando expostos às condições térmicas de uso.

Para a determinação do ponto de fusão e da capacidade de armazenamento térmico de PCMs, que sejam mais adequados para serem utilizados em componentes construtivos, vários autores indicam equações simplificadas que consideram regime semipermanente de trocas de calor (BAETENS; JELLE; GUSTAVSEN, 2010; PEIPPO; KAURANEN; LUND, 1991). Há também modelos matemáticos mais complexos e abrangentes que reproduzem o comportamento térmico desses materiais em regime transiente de trocas de calor, podendo ser utilizados em análises paramétricas do comportamento térmico de edifícios com PCMs (KUZNIK; VIRGONE; ROUX, 2008; PASUPATHY; VELRAJ, 2008). Com referência ao ponto de fusão, autores como Peippo, Kauranen e Lund (1991) sugerem que seja adotado um valor de 1 a $3{ }^{\circ} \mathrm{C}$ superior à temperatura média do ambiente.

No mercado internacional já se observam alguns produtos com PCMs que podem ser utilizados em revestimentos de paredes, forros ou divisórias internas. Esses materiais são parafinas ou sais hidratados encapsulados, apresentados na forma de pó ou líquido para serem aplicados como agregados de argamassas, em painéis, cápsulas ou filmes. Possuem capacidade de armazenamento térmico total entre 50 e $200 \mathrm{~kJ} / \mathrm{Kg}$, dos quais parte significativa refere-se à parcela latente, e ponto de fusão da ordem de 21 a $30{ }^{\circ} \mathrm{C}$. Esses materiais são fabricados por empresas europeias, asiáticas e norte-americanas, e comercializados para uso em edificações, geralmente localizadas no hemisfério norte (Tabela 1$)$ 
Tabela 1 - PCMs aplicáveis em paredes e forros de edificações disponíveis no mercado atualmente

\begin{tabular}{|c|c|c|c|c|c|c|}
\hline Empresa & Origem & Forma & Composição & $\begin{array}{l}\text { Ponto } \\
\text { de } \\
\text { Fusão } \\
\left({ }^{\circ} \mathbf{C}\right) \\
\end{array}$ & $\begin{array}{c}\text { Capacidade de } \\
\text { armazenamento } \\
\text { térmico latente } \\
(\mathbf{k J} / \mathbf{k g})\end{array}$ & $\begin{array}{c}\text { Capacidade de } \\
\text { armazenamento } \\
\text { térmico total } \\
(\mathrm{kJ} / \mathrm{kg})\end{array}$ \\
\hline \multirow{6}{*}{ A } & \multirow{6}{*}{ Alemanha } & \multirow{3}{*}{ Dispersão } & \multirow{6}{*}{$\begin{array}{l}\text { Parafina } \\
\text { microencapsulada }\end{array}$} & 26 & 45 & 59 \\
\hline & & & & 23 & 41 & 55 \\
\hline & & & & 21 & 37 & 51 \\
\hline & & \multirow{3}{*}{ Pó } & & 26 & 110 & 145 \\
\hline & & & & 23 & 100 & 135 \\
\hline & & & & 21 & 90 & 125 \\
\hline \multirow[b]{2}{*}{ B } & \multirow[b]{2}{*}{ Suécia } & \multirow[b]{2}{*}{ Não informado } & \multirow{2}{*}{$\begin{array}{l}\text { Sal hidratado } \\
\text { (sulfato de sódio + } \\
\text { aditivos) }\end{array}$} & 21 & 112 & 157 \\
\hline & & & & 24 & 151 & 196 \\
\hline $\mathrm{C}$ & $\begin{array}{l}\text { Estados } \\
\text { Unidos }\end{array}$ & Painel & $\begin{array}{l}\text { Polímero de } \\
\text { etileno + parafina }\end{array}$ & 21,7 & 70 & 140 \\
\hline \multirow{5}{*}{$\mathrm{D}$} & \multirow{5}{*}{$\begin{array}{l}\text { Estados } \\
\text { Unidos }\end{array}$} & \multirow{5}{*}{ Painéis, filmes } & \multirow{5}{*}{ Origem vegetal } & 20 & \multirow{5}{*}{-} & 180 \\
\hline & & & & 23 & & 203 \\
\hline & & & & 24 & & 185 \\
\hline & & & & 25 & & 185 \\
\hline & & & & 27 & & 200 \\
\hline $\mathrm{E}$ & China & $\begin{array}{l}\text { Esferas de } 50 \text { a } 100 \\
\text { mm de diâmetro, } \\
\text { espessura da parede } \\
\text { de } 0,5 \text { a } 1 \mathrm{~mm}\end{array}$ & $\begin{array}{l}\text { Mistura de sais } \\
\text { inorgânicos }\end{array}$ & 25 & 147,6 & - \\
\hline \multirow{6}{*}{$\mathrm{F}$} & \multirow{6}{*}{ Alemanha } & Forro de gesso & $\begin{array}{l}\text { Parafina } \\
\text { microencapsulada }\end{array}$ & 23 & $330\left(\mathrm{~kJ} / \mathrm{m}^{2}\right)$ & \multirow{6}{*}{ - } \\
\hline & & $\begin{array}{l}\text { Solução em galões } \\
\text { de } 1891\end{array}$ & \multirow{5}{*}{$\begin{array}{l}\text { Parafina } \\
\text { microencapsulada }\end{array}$} & 26 & \multirow{5}{*}{$\begin{array}{c}180-195 \\
\left(\mathrm{~kJ} / \mathrm{m}^{2}\right)\end{array}$} & \\
\hline & & $\begin{array}{l}\text { Pó em galões de } \\
1891\end{array}$ & & 28 & & \\
\hline & & & & $19-20$ & & \\
\hline & & & & $24-26$ & & \\
\hline & & & & $28-30$ & & \\
\hline
\end{tabular}

Fonte: tabela elaborada pelos autores a partir de dados disponíveis em sítios eletrônicos de fabricantes de PCMs aplicáveis em edificações.

Vários autores têm pesquisado a respeito do efeito do uso de PCMs como elemento de resfriamento passivo de edificações europeias e norteamericanas (AHMAD et al., 2006; ATHIENITIS et al., 1997; CABEZA et al., 2007; CHAN, 2011; PASUPATHY; VELRAJ, 2008; VOELKER; KORNADT; OSTRY, 2008; ZHANG; MEDINA; KING, 2005). De modo geral, os pesquisadores indicam que é possível ter uma redução de 2 a $4{ }^{\circ} \mathrm{C}$ no valor máximo da temperatura de recintos com PCMs, em comparação com ambientes compostos por materiais comuns.

Por outro lado, há referências escassas sobre a utilização de PCMs na envoltória de edificações em locais do hemisfério sul, com clima tropical, como é o caso do território brasileiro, possivelmente em virtude da ausência de fabricantes na região. Também não se tem informações suficientes sobre o efeito desses produtos no desempenho térmico de edificações nessa porção do planeta.
O objetivo deste trabalho é indicar intervalos de valores para os pontos de fusão e para a capacidade de armazenamento térmico latente de PCMs, aplicados em paredes e forro de cobertura, potencialmente mais adequados a edificações expostas às condições climáticas típicas de verão de cidades brasileiras. Essas informações são uma referência inicial para a seleção ou o desenvolvimento de produtos apropriados ao clima do país.

\section{Método}

Para atender ao objetivo proposto, foram efetuadas duas etapas de simulações do comportamento térmico de edificações com PCMs. Na primeira etapa de simulações, foi reproduzida a resposta térmica de um modelo originalmente construído em um laboratório em Lion, na França, que teve seu desempenho térmico analisado por Kuznik e Virgone (2009), em condições térmicas controladas. Os resultados das simulações computacionais desse modelo foram comparados 
aos obtidos nas medições efetuadas pelos referidos autores, tendo em vista verificar se os dados simulados apresentam a mesma ordem de grandeza dos valores obtidos nas medições. Quanto maior a similaridade entre os dados medidos e simulados, maior é a confiabilidade dos resultados das simulações, o que indica a adequação do programa para a realização de análises da resposta térmica de edifícios com PCMs (BRITO et al., 2015).

$\mathrm{Na}$ segunda etapa, foram feitas simulações paramétricas de modelos com fechamentos leves e pesados, com os PCMs utilizados no modelo francês, e com PCMs teóricos, cujas características consistem em variações na capacidade de armazenamento térmico latente e no ponto de fusão dos PCMs utilizados no modelo francês. Esses modelos foram simulados expostos às condições climáticas de oito cidades brasileiras. Nos itens a seguir são apresentados os procedimentos utilizados nas duas etapas de simulações.

\section{Simulações com o Programa EnergyPlus $^{\circledR}$}

O programa EnergyPlus ${ }^{\circledR}$ é voltado à simulação do comportamento térmico de edifícios considerando regime transiente de trocas de calor. Dos vários algoritmos disponíveis no programa, foi selecionado aquele baseado em diferenças finitas para simular materiais com características térmicas variáveis em função da temperatura, como é o caso dos PCMs. Os cálculos foram efetuados em intervalos de um minuto, para proporcionar maior precisão dos resultados.

Para efetuar as simulações de edificações com PCMs foram inseridos dados referentes à condutividade térmica e à entalpia do material em função da temperatura. Observa-se que esse programa já foi validado, a partir da versão 7.1, para a modelagem do comportamento térmico de PCMs (TABARES-VELASCO et al., 2012).

\section{Verificação da similaridade entre dados medidos e dados simulados}

O experimento efetuado por Kuznik e Virgone (2009), em condições controladas dentro de um laboratório, foi selecionado por disponibilizar todos os dados necessários à sua reprodução, o que não ocorre nos trabalhos de outros autores. O modelo tem duas células de teste, uma câmara climática e um simulador solar (Figura 1).

\section{Descrição do modelo}

A câmara climática é acoplada a um simulador solar com 12 lâmpadas, com potência de 1.000 W, que reproduzem o espectro solar. No experimento, o simulador solar e a câmara climática foram ajustados de modo que a temperatura do ar na câmara tenha variação de 15 a $30{ }^{\circ} \mathrm{C}$ e a radiação máxima incidente na fachada da célula de testes 1 seja da ordem de $180 \mathrm{~W} / \mathrm{m}^{2}$. Observa-se que os horários do dia no experimento não são coincidentes com horários de um dia real. A célula de testes 1 foi ventilada no período noturno a uma taxa de 3,8 Ren/h (renovações do volume de ar do ambiente por hora) e suas superfícies, como paredes, teto e piso, estão em contato com ar com temperatura igual a $20,5^{\circ} \mathrm{C}$.

$\mathrm{O}$ modelo foi analisado com e sem PCMs com ponto de fusão da ordem de $22{ }^{\circ} \mathrm{C}$, compostos de uma placa com $5 \mathrm{~mm}$ de espessura, feita com parafinas e polímeros microencapsulados com capacidade de armazenamento térmico latente de $70 \mathrm{~kJ} / \mathrm{kg}$. Nas situações com PCMs, esse material foi adicionado a três paredes da célula 1 . A curva de entalpia do material, obtida de Cao, Gustavsen e Uvsløkk (2010), é indicada na Figura 2. As características dos componentes e materiais são indicadas na Figura 3 e nas Tabelas 2 e 3.

\section{Medições efetuadas por Kuznik e Virgone (2009)}

Kuznik e Virgone (2009) efetuaram medições da temperatura do ar no centro da célula de testes 1 , em duas alturas (a $0,85 \mathrm{~m}$ do piso e a $1,7 \mathrm{~m}$ do piso) e medições das temperaturas superficiais das paredes, ambos com termopares com precisão de $0,4{ }^{\circ} \mathrm{C}$. A radiação incidente no vidro foi medida com um piranômetro. Os dados foram medidos por três dias, com aquisição a cada 10 min. 
Figura 1 - Projeto da câmara de testes

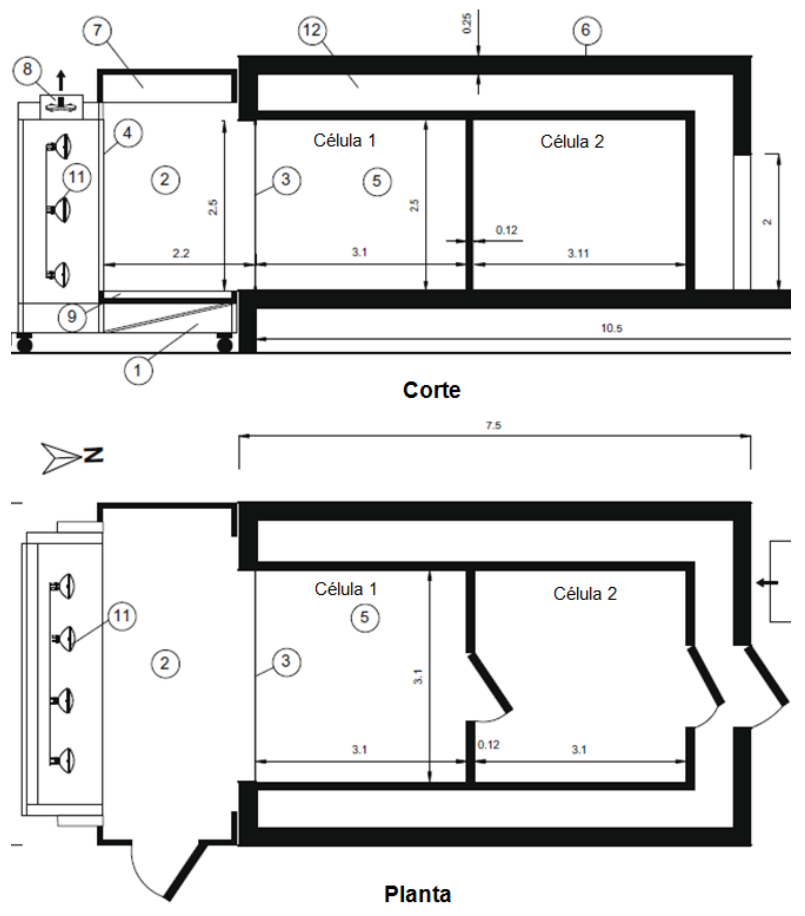

Fonte: traduzido de Kuznik e Virgone (2009).

Nota: Legenda:
1. Ar condicionado;
2. Câmara climática;
3. Vidro simples;
4. Pano de vidro de proteção do simulador solar;
5. Célula de teste;
6. Concreto;
7. Plenum;
8. Ventilador;
9. Retorno;
10. Unidade de ar condicionado;
11. Simulador solar; e
12. Envoltória das células de teste.

Figura 2 - Entalpia em função da temperatura do painel com PCM

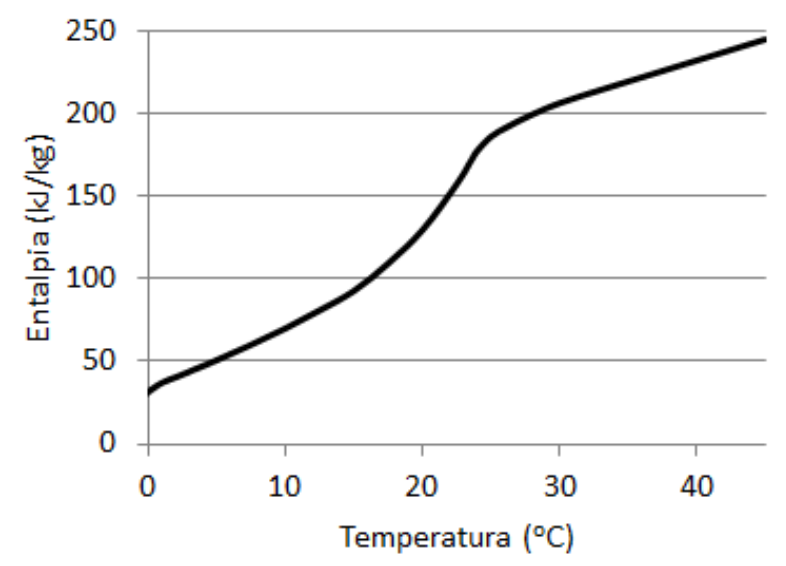

Fonte: adaptado de Cao, Gustavsen e Uvsløkk (2010). 
Figura 3 - Paredes com e sem PCM
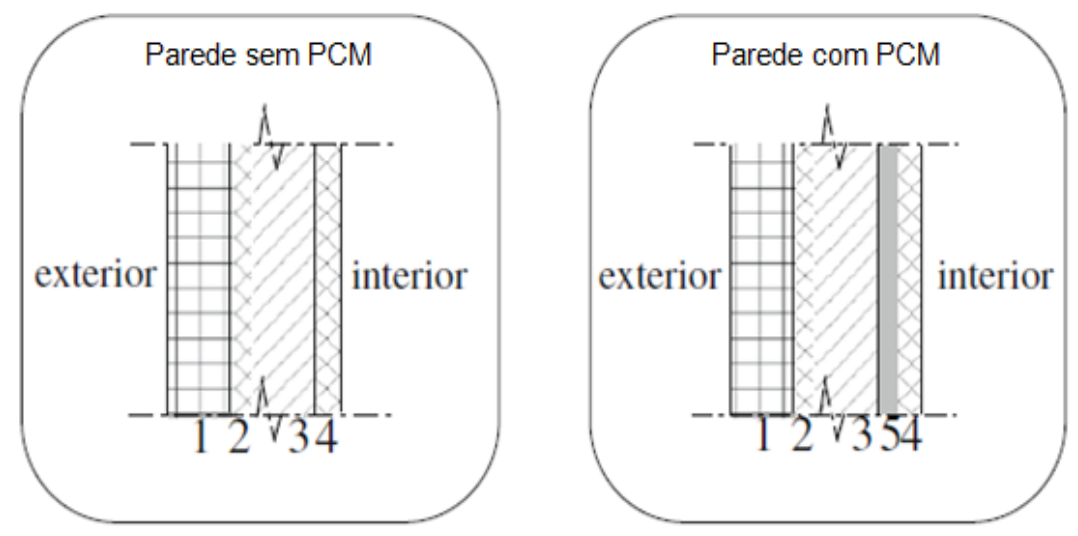

1. Placa de madeira; 2. Gesso; 3. Poliestireno; 4. Gesso; 5. PCM

Fonte: traduzido de Kuznik, Virgone e Roux (2008) e Kuznik e Virgone (2009).

Tabela 2 - Composição das paredes, piso e teto do modelo

\begin{tabular}{l|l|c}
\hline \multicolumn{1}{c|}{ Componente } & \multicolumn{1}{c|}{ Material } & Espessura (mm) \\
\hline Piso & Concreto & 200 \\
\hline \multirow{3}{*}{ Parede } & Gesso & 10 \\
& Poliestireno expandido & 50 \\
& Gesso & 10 \\
& Placa de madeira (face externa) & 50 \\
\hline \multirow{3}{*}{ Teto } & Gesso & 10 \\
& Placa de madeira & 8 \\
& Isolante térmico & 55 \\
\hline Fachada & Placa de madeira (face externa) & 25 \\
\hline
\end{tabular}

Fonte: traduzido de Kuznik, Virgone e Roux (2008) e Kuznik e Virgone (2009).

Tabela 3 - Características térmicas dos materiais do modelo

\begin{tabular}{l|c|c}
\hline & Massa específica $\left(\mathbf{k g} / \mathbf{m}^{3}\right)$ & Condutividade térmica (W/m.K) \\
\hline Concreto & 400 & 0,160 \\
Gesso & 817 & 0,350 \\
Placa de madeira & 544 & 0,136 \\
Poliestireno expandido & 35 & 0,040 \\
Isolante térmico & 200 & 0,060 \\
Vidro & 2500 & 1 \\
PCM & 900 & 0,18 (sólido) e 0,22 (líquido) \\
\hline
\end{tabular}

Fonte: Kuznik e Virgone (2009).

Simulações computacionais da resposta térmica do modelo francês

Em virtude de limitações do programa EnergyPlus $^{\circledR}$, não foi possível reproduzir as características exatas do simulador solar. Foi feita uma adaptação de dados climáticos de uma cidade fictícia que representa as condições de exposição do modelo original quanto à temperatura do ar e radiação incidente na fachada. Nas Figuras 4 e 5 são apresentados, respectivamente, gráficos com os perfis horários da temperatura do ar exterior e da radiação incidente na fachada, considerados no modelo e nas simulações.

O modelo foi simulado de acordo com as características e dimensões dos recintos originais, sendo cada ambiente uma zona térmica. A fachada é voltada ao exterior e as demais superfícies são voltadas a ambientes internos com temperatura de $20,5{ }^{\circ} \mathrm{C}$. Verificou-se que no modelo simulado ocorre perda de calor da fachada para o fundo de céu no período noturno, o que não acontece no modelo original por estar acondicionado no

130 Brito, A. C. de; Akutsu, M.; Salles, E. M.; Castro, G. M. 
interior do laboratório e, portanto, protegido do clima. Esse fenômeno é observado na Figura 6, em que é apresentado gráfico da temperatura horária da superfície da fachada do modelo simulado e a temperatura do ar exterior, destacando-se que a temperatura mínima superficial da fachada é inferior à temperatura mínima do ar exterior no período noturno. Em virtude dessa ocorrência, para obter as mesmas condições térmicas do modelo original, foi necessário utilizar uma taxa de ventilação noturna inferior, de 1 Ren/h (renovação do volume de ar do ambiente por hora), enquanto no modelo original é utilizada uma taxa de 3,8 Ren/h.

\section{Simulações com PCMs teóricos em localidades brasileiras}

$\mathrm{Na}$ segunda etapa foram realizadas simulações da resposta térmica de modelos expostos às condições climáticas de dias típicos de verão de cidades representantes das oito zonas bioclimáticas brasileiras. Nas Tabelas 4 e 5 são apresentados, respectivamente, os dados geográficos e climáticos dos dias típicos de verão das cidades consideradas. As referidas cidades foram selecionadas em virtude da disponibilidade de todos os dados climáticos necessários à realização das simulações.

Figura 4 - Gráfico da temperatura do ar exterior nas medições de Kuznik, Virgone e Roux (2008) e Kuznik e Virgone (2009)

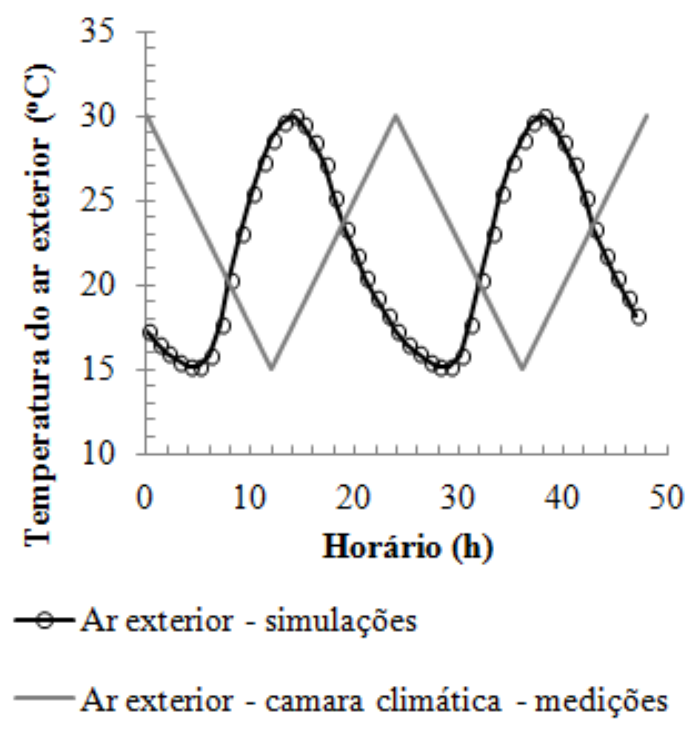

Figura 5 - Gráfico da radiação incidente na fachada nas medições e nas simulações do presente estudo

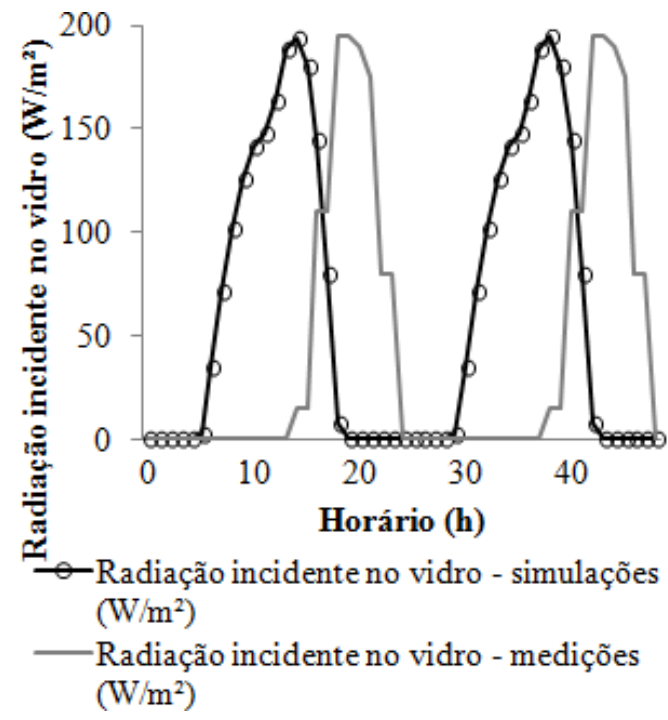

Fonte: dados medidos adaptados de Kuznik e Virgone (2009), dados simulados obtidos pelos autores do presente estudo). 
Figura 6 - Gráfico da temperatura superficial da fachada e temperatura do ar exterior no modelo simulado

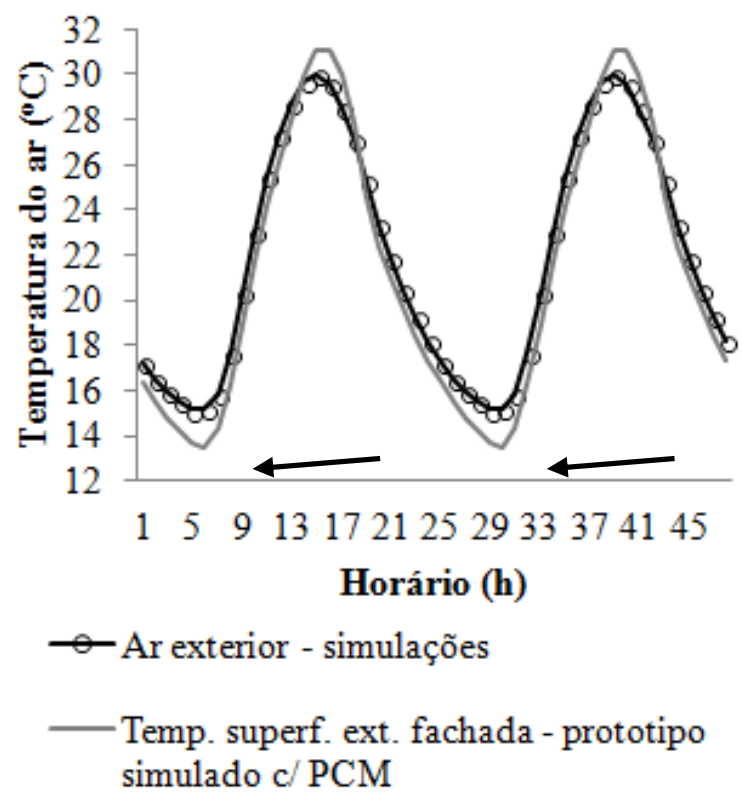

Nota: em destaque, setas apontam a menor temperatura da fachada à noite indicando perda de calor para o fundo de céu nas simulações, que não ocorrem no modelo real francês.

Tabela 4 - Dados geográficos das cidades

\begin{tabular}{c|l|c|c|c|c}
\hline $\begin{array}{c}\text { Zona } \\
\text { bioclimática }\end{array}$ & \multicolumn{1}{|c|}{ Cidade } & UF & Latitude & Longitude & Altitude [m] \\
\hline 1 & Curitiba & PR & $25,42 \mathrm{~S}$ & $49,27 \mathrm{~W}$ & 924 \\
2 & São Lourenço & MG & $22,1 \mathrm{~S}$ & $45,01 \mathrm{~W}$ & 953 \\
3 & São Paulo & SP & $23,5 \mathrm{~S}$ & $46,62 \mathrm{~W}$ & 792 \\
4 & Brasília & DF & $15,78 \mathrm{~S}$ & $47,93 \mathrm{~W}$ & 1160 \\
5 & Vitória da Conquista & BA & $14,88 \mathrm{~S}$ & $40,79 \mathrm{~W}$ & 875 \\
6 & Campo Grande & MS & $20,45 \mathrm{~S}$ & $54,62 \mathrm{~W}$ & 530 \\
7 & Cuiabá & MT & $15,55 \mathrm{~S}$ & $56,12 \mathrm{~W}$ & 151 \\
8 & Manaus & AM & $3,13 \mathrm{~S}$ & $60,02 \mathrm{~W}$ & 72 \\
\hline
\end{tabular}

Fonte: ABNT (2013). 
Tabela 5 - Dados de dias típicos de verão das cidades

\begin{tabular}{|c|c|c|c|c|c|}
\hline Cidade & $\begin{array}{l}\text { Valor máximo } \\
\text { diário da } \\
\text { temperatura do } \\
\operatorname{ar}\left({ }^{\circ} \mathrm{C}\right)\end{array}$ & $\begin{array}{c}\text { Amplitude } \\
\text { diária da } \\
\text { temperatura } \\
\text { do } \text { ar }\left({ }^{\circ} \mathrm{C}\right)\end{array}$ & $\begin{array}{c}\text { Temperatura } \\
\text { de bulbo } \\
\text { úmido }\left({ }^{\circ} \mathrm{C}\right)\end{array}$ & $\begin{array}{c}\text { Radiação solar } \\
\text { global - plano } \\
\text { horizontal } \\
\left(\mathbf{W h} / \mathbf{m}^{2}\right)\end{array}$ & $\begin{array}{c}\text { Temperatura } \\
\text { do solo a } 1 \mathrm{~m} \\
\text { de } \\
\text { profundidade } \\
\left({ }^{\circ} \mathrm{C}\right)^{\mathrm{c}}\end{array}$ \\
\hline Curitiba & 31,4 & 10,2 & 21,3 & $4988^{b}$ & 20 \\
\hline São Lourenço ${ }^{a}$ & 31,8 & 11,7 & 21,6 & $5307^{\mathrm{b}}$ & 23 \\
\hline São Paulo & 31,9 & 9,2 & 21,3 & 5180 & 21 \\
\hline Brasília & 31,2 & 12,5 & 20,9 & 4625 & 22,3 \\
\hline $\begin{array}{l}\text { Vitória da } \\
\text { Conquista }^{\mathrm{a}}\end{array}$ & 31,7 & 10,3 & 21,0 & $5030^{\mathrm{b}}$ & 23,6 \\
\hline Campo Grande & 33,6 & 10,0 & 23,6 & 5481 & 25 \\
\hline Cuiabá & 37,8 & 12,4 & 24,8 & 4972 & 26 \\
\hline Manaus & 34,9 & 9,1 & 26,4 & 5177 & 26 \\
\hline
\end{tabular}

Fonte: ABNT (2013).

Legenda: Nota:

${ }^{a}$ Os dados climáticos dos dias típicos de projeto desta cidade não constam na norma NBR 15575 (ABNT, 2013), foram gerados pelos autores do presente estudo com base em dados climáticos do INMET e dados de radiação solar global no plano horizontal obtidos do CRESESP CEPEL;

balor de radiação solar global obtido pelo CRESESP CEPEL; e

'Dados não constam na referida norma. Foram selecionados a partir de dados climáticos disponíveis no sítio eletrônico do programa EnergyPlus ${ }^{\circledR}$ (USDOE, 2015).

Observação: como na norma NBR 15575 (ABNT, 2013) não são indicados todos os dados climáticos necessários às simulações, adotou-se velocidade do vento igual a $1 \mathrm{~m} / \mathrm{s}$, voltado à direção norte, no solstício de verão, como padrão nas simulações, por serem valores passíveis de ocorrerem em localidades brasileiras, com base na observação de dados climáticos disponíveis no sítio eletrônico do programa EnergyPlus ${ }^{\circledR}$ (USDOE, 2015).

\section{Características da edificação}

Com o intuito de ter informações do efeito da adição de PCMs no desempenho térmico de edificações brasileiras, adotou-se um modelo como referência das análises. Assim, não foram consideradas questões relativas a variáveis do projeto arquitetônico e outras condições de exposição ao clima que também podem afetar a sua resposta térmica. A edificação utilizada nas simulações tem seção quadrada, com dimensão $2,60 \mathrm{~m}$ e pé-direito variável de $2,60 \mathrm{~m}$ a $3 \mathrm{~m}$. Na fachada oeste há uma área envidraçada de $1 \mathrm{~m}^{2}$ composta de vidro comum transparente com $3 \mathrm{~mm}$ de espessura.

Foram considerados dois sistemas construtivos com diferentes inércias térmicas, um "leve" e outro "pesado", nos quais os PCMs foram aplicados em todas as superfícies internas opacas, exceto piso e porta. Os sistemas são descritos a seguir:

(a) sistema "leve": paredes com chapa cimentícia de $1 \mathrm{~cm}$ na face externa e placa de $1,2 \mathrm{~cm}$ de gesso acartonado na face interna da parede. $\mathrm{O}$ espaço entre as placas é preenchido com $5 \mathrm{~cm}$ de lã de rocha. A edificação tem forro de $1,2 \mathrm{~cm}$ de gesso acartonado e cobertura em telhado de telhas cerâmicas; e

(b) sistema "pesado": paredes e forro compostos de $15 \mathrm{~cm}$ de concreto convencional e telhado com telhas cerâmicas.
As características dos materiais tradicionais são indicadas na Tabela 6 e a descrição dos PCMs utilizados nas simulações é apresentada no item posterior.

\section{Características dos PCMs considerados nas simulações}

Em edificações ventiladas naturalmente, expostas às condições climáticas de verão de várias localidades brasileiras, é comum ocorrer temperaturas do ar interior substancialmente maiores que $22{ }^{\circ} \mathrm{C}$, que é o valor do ponto de fusão dos PCMs utilizados por Kuznik e Virgone (2009). Nessa situação, em tese, o produto não teria potencial para proporcionar melhorias significativas no desempenho térmico de edificações nesses locais.

Diante disso, foi analisada a resposta térmica de um modelo considerando esse PCM em suas características originais, quanto à capacidade de armazenamento térmico latente e ponto de fusão, além de se efetuar um estudo teórico com variações nessas características, totalizando 16 tipos de PCMs. São abordados materiais com temperaturas de ponto de fusão mais elevadas, da ordem de grandeza das temperaturas do ar exterior que ocorrem em cidades brasileiras, e maior capacidade de armazenamento térmico latente, considerando espessuras do produto que correspondem de uma a quatro vezes o valor 
original. Na Tabela 7 são apresentados os valores da espessura, da densidade superficial, do ponto de fusão e da capacidade de armazenamento térmico latente dos PCMs utilizados nas simulações.

Destaca-se que, por ser um estudo teórico inicial, não há, necessariamente, produtos no mercado com as características analisadas. Além disso, não foram abordadas alterações físicas, químicas ou de outra natureza que seriam necessárias à obtenção dessas características, bem como para a manutenção dos ciclos de mudança de fase, quanto à durabilidade do material ou referentes aos custos envolvidos em sua produção, fatores importantes para o desenvolvimento e comercialização de produtos com esses materiais, mas que não fazem parte do escopo do estudo.

\section{Condições analisadas}

O modelo foi simulado com todas as paredes expostas à radiação solar direta, sem sombreamento de aberturas e com taxa de ventilação de $1 \mathrm{Ren} / \mathrm{h}$ (renovação do volume de ar do ambiente por hora), com base nos procedimentos da norma NBR 15575 (ABNT, 2013).

\section{Critérios de análise}

$\mathrm{Na}$ etapa 1 foi verificada a similaridade entre os valores medidos e simulados das temperaturas do ar e das temperaturas das superfícies internas de paredes. Quanto menor a diferença nos valores das grandezas medidas e simuladas, maior a confiabilidade dos resultados das simulações, fornecendo subsídios para a realização da segunda etapa do trabalho. Na etapa 2 analisou-se o efeito dos PCMs na resposta térmica da edificação tendo como referência as amplitudes diárias e os valores das temperaturas do ar exterior e interior. Quanto menor a amplitude diária e a temperatura máxima do ar interior em relação ao ar exterior, maior é a inércia térmica do recinto. Verificou-se também o atendimento de dois critérios, o primeiro referente ao nível "Mínimo" de desempenho térmico segundo a norma NBR 15575 (ABNT, 2013). Para atendimento desse critério, no período de verão o valor da temperatura máxima do ar interior deve ser menor ou igual ao valor máximo da temperatura do ar exterior. O segundo critério é relacionado ao conforto térmico do usuário. Com base na norma ASHRAE 55 (ASHRAE, 2013) e Akutsu (1998), foi verificado se os valores da temperatura do ar interior estão compreendidos no intervalo entre $22{ }^{\circ} \mathrm{C}$ e $29^{\circ} \mathrm{C}$.

Tabela 6 - Características térmicas dos materiais tradicionais

\begin{tabular}{l|c|c|c|c}
\hline & $\begin{array}{c}\text { Massa } \\
\text { específica } \\
\left(\mathbf{k g} / \mathbf{m}^{3}\right)\end{array}$ & $\begin{array}{c}\text { Calor } \\
\text { específico } \\
(\mathbf{J} / \mathbf{k g . K})\end{array}$ & $\begin{array}{c}\text { Condutividade } \\
\text { térmica }(\mathbf{W} / \mathbf{m} . \mathbf{K})\end{array}$ & $\begin{array}{c}\text { Absortância à radiação } \\
\text { solar da superfície } \\
\text { externa }\end{array}$ \\
\hline Concreto/chapa & 2400 & 1000 & 1,75 & 0,3 \\
cimentícia & 817 & 1620 & 0,35 & - \\
Gesso acartonado & 10 & 1000 & 0,04 & - \\
Lã de rocha & 1300 & 920 & 0,7 & 0,7 \\
Cerâmica & \multicolumn{2}{|}{} \\
\hline
\end{tabular}

Fonte: ABNT (2008).

Tabela 7 - Características térmicas dos PCMs

\begin{tabular}{|c|c|c|c|c|c|c|c|}
\hline Tipo de PCM & $\begin{array}{c}\text { Espessura } \\
(\mathbf{m m})\end{array}$ & $\begin{array}{l}\text { Densidade } \\
\text { superficial }\end{array}$ & $\begin{array}{c}\text { Capacidade de } \\
\text { armazenamento térmico }\end{array}$ & \multicolumn{4}{|c|}{ Ponto de fusão $\left({ }^{\circ} \mathrm{C}\right)$} \\
\hline PCMs originais $^{a}$ & 5 & 4,5 & 315 & \multicolumn{4}{|c|}{22} \\
\hline \multirow{4}{*}{ PCMs teóricos ${ }^{b}$} & 5 & 4,5 & 315 & - & \multirow{4}{*}{26} & \multirow{4}{*}{30} & \multirow{4}{*}{34} \\
\hline & 10 & $9^{c}$ & 630 & \multirow{3}{*}{22} & & & \\
\hline & 15 & $13,5^{\mathrm{c}}$ & 945 & & & & \\
\hline & 20 & $18^{\mathrm{c}}$ & 1260 & & & & \\
\hline
\end{tabular}

Nota: Legenda:

${ }^{a}$ Características originais do produto, espessura de $5 \mathrm{~mm}$, massa específica de $900 \mathrm{~kg} / \mathrm{m}^{3}$, placa com 1,2 $\mathrm{m}^{2}$, com massa de 5,4 kg, capacidade de armazenamento térmico latente de $70 \mathrm{~kJ} / \mathrm{kg}$ (KUZNIK; VIRGONE, 2009);

${ }^{\mathrm{b}}$ Características consideradas no presente estudo;

'Valores estimados pelos autores do presente estudo com base nos dados dos PCMs originais, dimensões da placa de material e a sua massa total; e

dValores estimados pelos autores do presente estudo considerando-se os valores de densidade superficial obtidos para cada espessura do produto e a capacidade de armazenamento térmico latente de $70 \mathrm{~kJ} / \mathrm{kg}$ dos PCMs originais.

134 Brito, A. C. de; Akutsu, M.; Salles, E. M.; Castro, G. M. 


\section{Resultados e análises}

Nos itens a seguir são apresentados, respectivamente, os resultados obtidos nas etapas 1 e 2 do trabalho.

\section{Etapa 1}

Nas Figuras 7 e 8 são indicados gráficos dos valores das temperaturas do ar e das superfícies de uma parede do modelo, obtidas por meio das medições (KUZNIK; VIRGONE, 2009) e das simulações computacionais do presente estudo.

\section{Temperatura do ar na célula 1}

No modelo sem PCMs, os valores da temperatura máxima do ar interior, obtidos por medição e por simulações, não apresentam diferenças significativas (Figura 7), sendo, respectivamente,
$35,3{ }^{\circ} \mathrm{C}$ e $35,2{ }^{\circ} \mathrm{C}$. Por outro lado, os valores da temperatura mínima do ar interior apresentam diferença mais significativa, da ordem de $0,7{ }^{\circ} \mathrm{C}$, entre o valor medido e simulado, respectivamente $18,9{ }^{\circ} \mathrm{C}$ e $18,2{ }^{\circ} \mathrm{C}$. Entretanto, essa diferença é aceitável uma vez que os valores apresentaram a mesma ordem de grandeza.

Esse resultado é decorrente das perdas de calor que ocorrem no modelo simulado para o fundo de céu no período noturno, como já foi mencionado anteriormente. Esse fator afeta, de modo mais significativo, a resposta térmica dos recintos sem PCMs, situação em que o sistema construtivo possui menor inércia térmica. No modelo com PCMs, não há diferenças significativas entre os valores da temperatura do ar medidos e simulados (diferença de $0,3{ }^{\circ} \mathrm{C}$ entre as temperaturas máximas e $0,1{ }^{\circ} \mathrm{C}$ entre as mínimas).

Figura 7 - Gráficos da temperatura do ar interior nas simulações do presente estudo (à esquerda) e nas medições de Kuznik e Virgone $(2008,2009)$ (à direita)
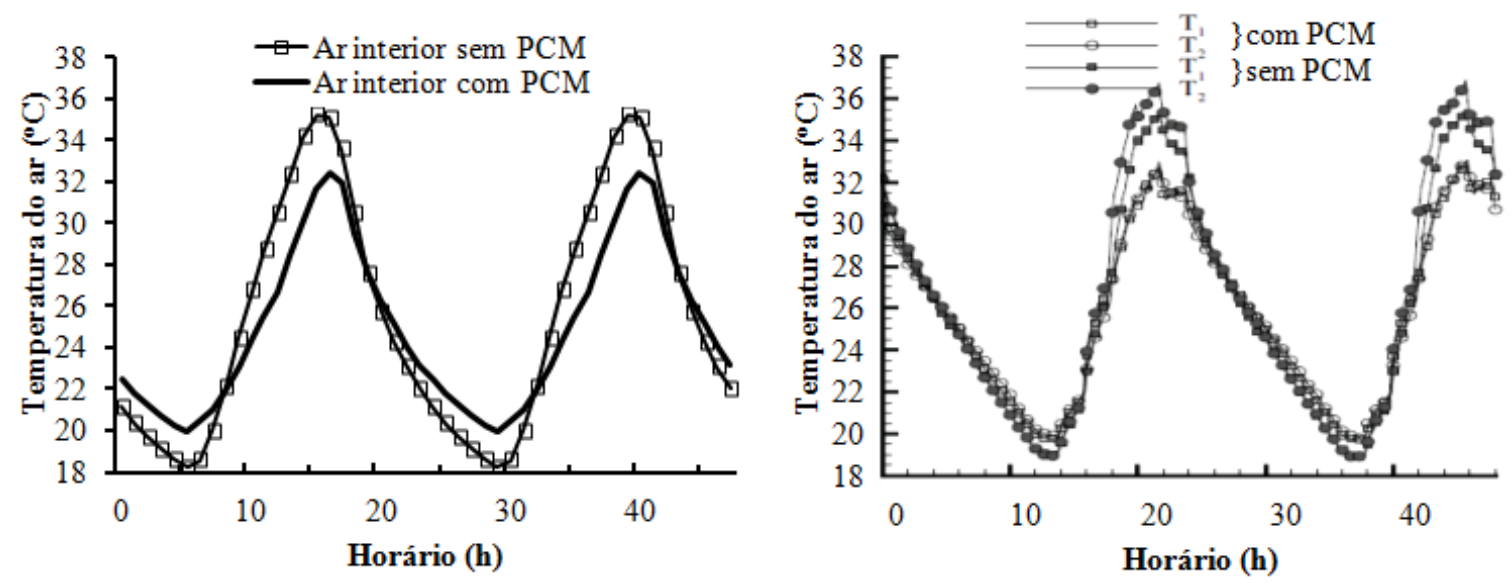

Fonte: autores do presente estudo e gráfico adaptado de Kuznik e Virgone (2009).

Figura 8 - Gráficos da temperatura superficial da parede do fundo da câmara de testes nas simulações do presente estudo (à esquerda) e nas medições de Kuznik e Virgone (2009) (à direita)
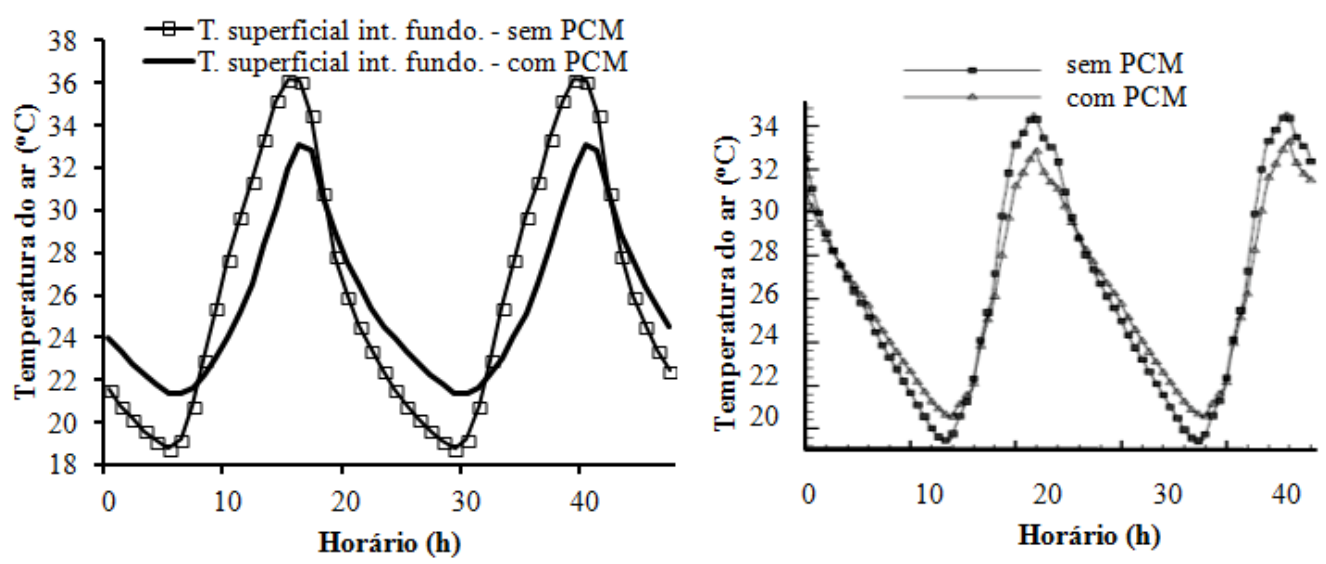

Fonte: autores do presente estudo e gráfico adaptado de Kuznik e Virgone (2009). 


\section{Temperatura superficial de parede da célula 1}

No modelo sem PCMs observou-se uma diferença da ordem de $2{ }^{\circ} \mathrm{C}$ entre os valores máximos da temperatura superficial da parede nas medições e simulações $\left(34,2{ }^{\circ} \mathrm{C}\right.$ nas medições e $36,7{ }^{\circ} \mathrm{C}$ nas simulações), como indicado na Figura 8. Isso também é observado nas temperaturas mínimas superficiais, com diferenças entre os valores medidos e simulados de $1,1^{\circ} \mathrm{C}\left(19,8{ }^{\circ} \mathrm{C}\right.$ medido e $18,7{ }^{\circ} \mathrm{C}$ simulado). Por outro lado, no modelo com PCMs a diferença entre valores das temperaturas superficiais, medidos e simulados, é da ordem de $0,8^{\circ} \mathrm{C}$.

Isso acontece pois nas simulações não são reproduzidas com exatidão as condições térmicas do modelo, principalmente quanto às trocas térmicas que ocorrem por convecção que influenciam o valor da temperatura superficial dos fechamentos. Todavia, como as trocas térmicas majoritárias ocorrem por radiação, as temperaturas superficiais não afetam de modo significativo os valores da temperatura do ar interior, que representa a resposta térmica do recinto.

\section{Considerações}

Mesmo diante das adaptações que foram necessárias para reproduzir a resposta térmica do modelo, por meio de simulações computacionais, os resultados simulados e medidos apresentaram a mesma ordem de grandeza. Tais adaptações não se referem à capacidade do programa em moderar o comportamento térmico dos PCMs, mas, sim, quanto às características físicas do modelo original. Dessa forma, o programa EnergyPlus ${ }^{\circledR}$ mostrou-se promissor para ser usado na avaliação do desempenho térmico de ambientes com PCMs. Esses resultados proporcionam também maior confiabilidade das simulações para a realização dos estudos da segunda etapa do trabalho.

\section{Etapa 2}

Nos itens a seguir são apresentados os resultados obtidos, respectivamente, para os modelos com sistema construtivo pesado e leve.

\section{Recintos compostos por sistema construtivo pesado}

O acréscimo de PCMs, em suas características originais no modelo com sistema construtivo pesado, proporcionou uma redução da ordem de até $0,4{ }^{\circ} \mathrm{C}$ no valor máximo da temperatura do ar interior, em comparação com o recinto sem esses materiais. Com os PCMs teóricos, essa redução foi de até $1,5^{\circ} \mathrm{C}$, como indicado no gráfico da Figura 9. No referido gráfico são apresentados os valores horários das temperaturas do ar exterior e no interior de um modelo sem PCMs e com PCMs com ponto de fusão de $30{ }^{\circ} \mathrm{C}$ e várias espessuras, na zona bioclimática 3 . Este gráfico ilustra situações nas quais o recinto apresentou maior inércia térmica.

Esses resultados indicam que o modelo com sistema construtivo pesado já apresenta inércia térmica significativa, tendo seu desempenho térmico pouco afetado pela capacidade de armazenamento térmico adicional propiciada pelos PCMs, especialmente se forem considerados os PCMs em suas características originais.

Figura 9 - Gráfico da temperatura do ar exterior e no interior de modelo com sistema pesado, sem PCMs e com PCMs com ponto de fusão de $30{ }^{\circ} \mathrm{C}$

\section{Z3 - Sistema Pesado - PCM c/ Ponto de fusão de $30^{\circ} \mathrm{C}$}

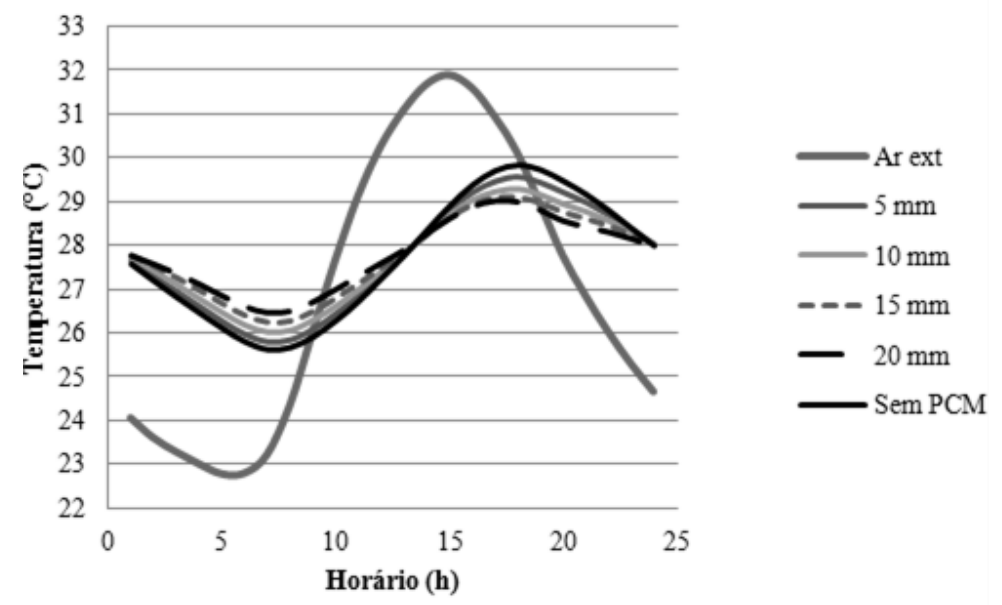

136 Brito, A. C. de; Akutsu, M.; Salles, E. M.; Castro, G. M. 


\section{Recintos compostos de sistema construtivo leve}

Nas Figuras 10 a 13 são apresentados gráficos dos intervalos da temperatura do ar em modelos sem PCMs e com PCMs, nas oito zonas bioclimáticas brasileiras, considerando os PCMs originais e os PCMs teóricos, para os vários valores do ponto de fusão e capacidade de armazenamento térmico latente total do material (espessuras de $5 \mathrm{~mm}$ a 20 $\mathrm{mm}$, que correspondem, respectivamente, à capacidade de armazenamento térmico latente de $315 \mathrm{~kJ} / \mathrm{m}^{2}$ a $1260 \mathrm{~kJ} / \mathrm{m}^{2}$ ). Na Tabela 8 é indicada a diferença entre os valores das temperaturas máximas do ar interior com e sem esses materiais na edificação.

Em todas as zonas bioclimáticas brasileiras, nos modelos com PCMs ocorreu uma redução nos valores da amplitude diária e da temperatura máxima do ar interior, em comparação com situações sem esses materiais. Esse fenômeno ocorre, especialmente, com o aumento da capacidade de armazenamento térmico latente do produto e do seu ponto de fusão (PCMs teóricos).

Nos modelos compostos de sistema construtivo leve com PCMs em suas características originais, ocorreu uma redução no valor máximo da temperatura do ar interior da ordem de $0,6{ }^{\circ} \mathrm{C}$ a 1,6 ${ }^{\circ} \mathrm{C}$ em relação à temperatura máxima do ar em recintos sem PCMs, dependendo do clima do local. Nas zonas bioclimáticas com maior valor da temperatura do ar exterior (Z6 a Z8), o efeito do material no desempenho térmico do edifício foi menos significativo do que nas demais zonas bioclimáticas (Z1 a Z5).

Figura 10 - Intervalos de temperatura do ar interior com sistema leve, sem PCMs e com PCMs na Z1 e $\mathrm{Z2}$, respectivamente
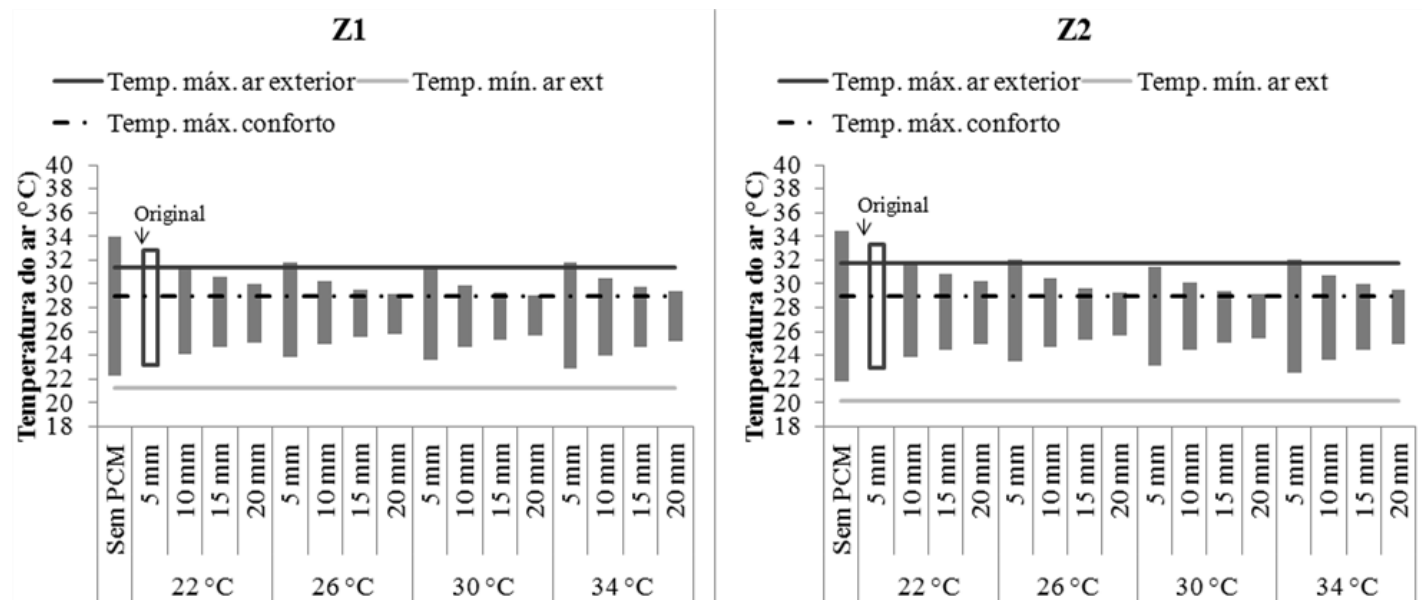

Figura 11 - Intervalos de temperatura do ar interior com sistema leve, sem PCMs e com PCMs na Z3 e $Z 4$, respectivamente
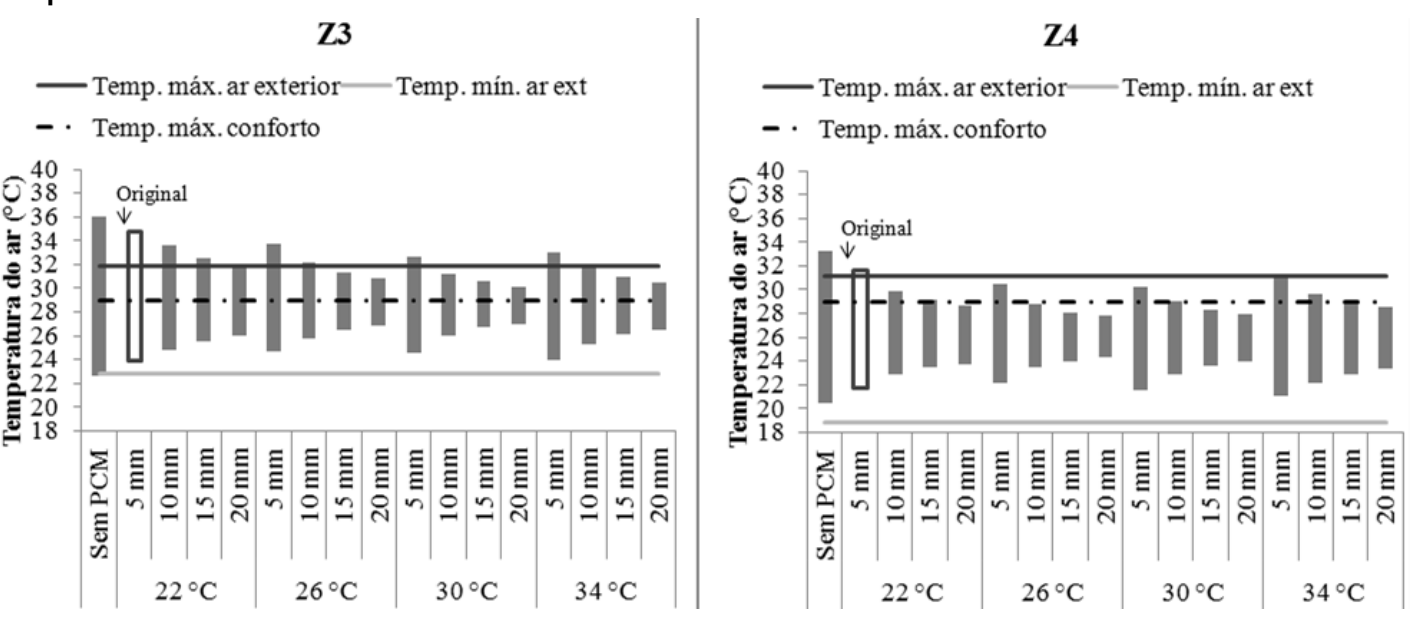
Figura 12 - Intervalos de temperatura do ar interior com sistema leve, sem PCMs e com PCMs na Z5 e $\mathrm{Z6}$, respectivamente
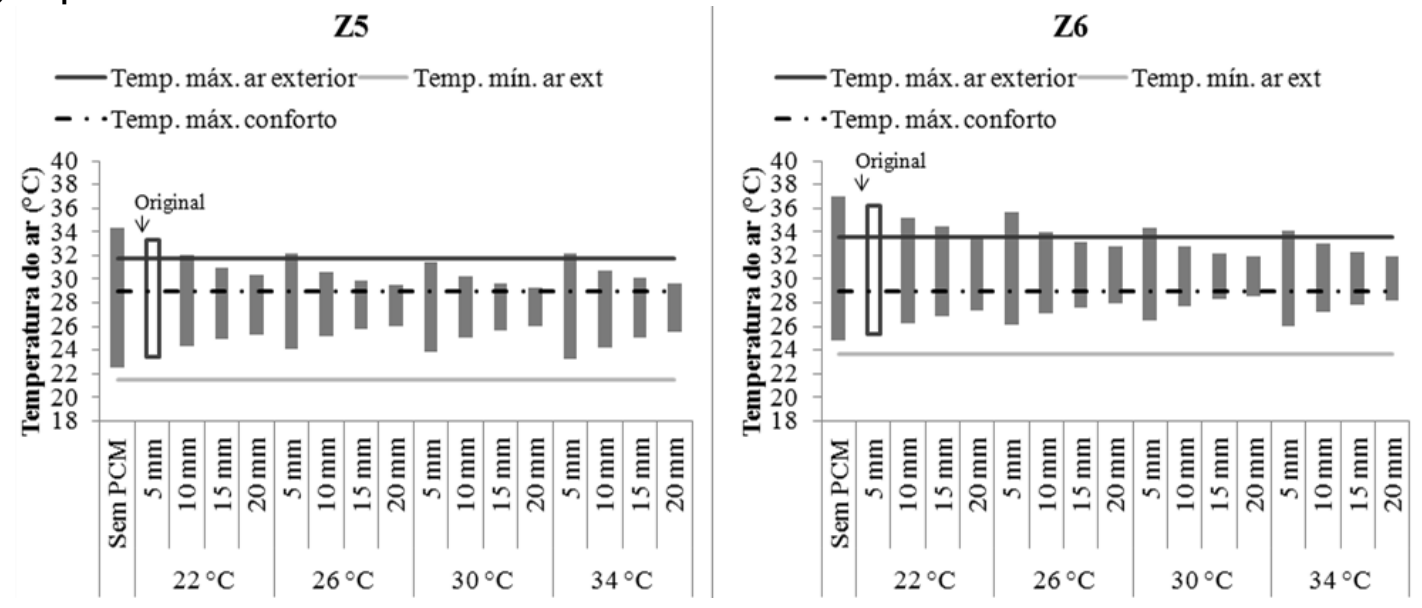

Figura 13 - Intervalos de temperatura do ar interior com sistema leve, sem PCMs e com PCMs na Z7 e Z8, respectivamente
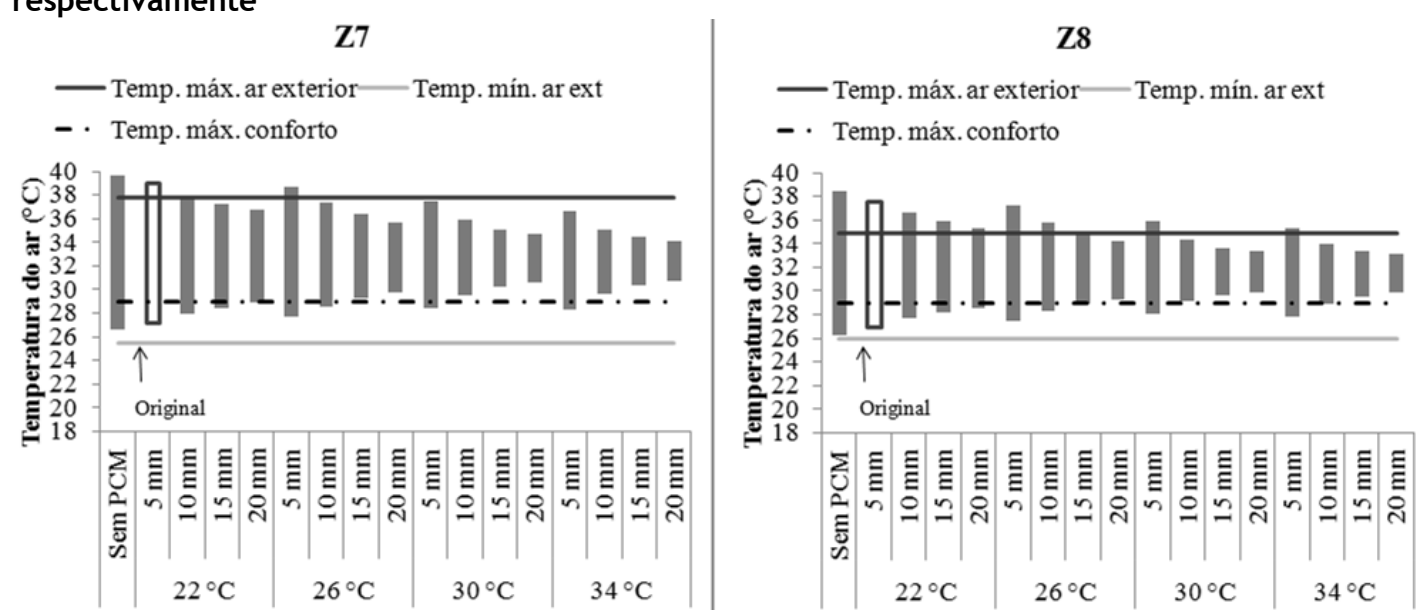

Tabela 8 - Redução no valor da temperatura máxima do ar interior em recintos com PCMs em relação à situação sem PCMs

\begin{tabular}{|c|c|c|c|c|c|c|c|c|c|c|c|}
\hline \multirow[t]{2}{*}{ PCMs } & \multirow{2}{*}{$\begin{array}{c}\text { Ponto } \\
\text { de fusão } \\
\left({ }^{\circ} \mathrm{C}\right)\end{array}$} & \multirow{2}{*}{$\begin{array}{l}\text { Espessura } \\
\quad(\mathbf{m m})\end{array}$} & \multirow{2}{*}{$\begin{array}{c}\text { Capacidade de } \\
\text { armazenamento térmico } \\
\text { latente }\left(\mathrm{kJ} / \mathrm{m}^{2}\right)\end{array}$} & \multicolumn{8}{|c|}{$\begin{array}{l}\text { Temp. máx. ar interior sem PCMs - Temp. máx } \\
\text { ar interior com PCMs }\end{array}$} \\
\hline & & & & $\mathrm{Z1}$ & $\mathbf{Z 2}$ & Z3 & Z4 & $\mathrm{Z5}$ & Z6 & $\mathbf{Z 7}$ & $\mathbf{Z 8}$ \\
\hline Originais & 22 & 5 & 315 & 1,1 & 1,2 & 1,2 & 1,6 & 1,0 & 0,7 & 0,6 & 0,8 \\
\hline \multirow{15}{*}{ Teóricos } & \multirow{3}{*}{22} & 10 & 630 & 2,4 & 2,6 & 2,5 & 3,3 & 2,4 & 1,8 & 1,6 & 1,8 \\
\hline & & 15 & 945 & 3,4 & 3,7 & 3,5 & 4,1 & 3,4 & 2,6 & 2,4 & 2,5 \\
\hline & & 20 & 1260 & 4,0 & 4,3 & 4,2 & 4,5 & 4,0 & 3,2 & 2,9 & 3,1 \\
\hline & \multirow{4}{*}{26} & 5 & 315 & 2,2 & 2,5 & 2,4 & 2,8 & 2,2 & 1,3 & 1,0 & 1,2 \\
\hline & & 10 & 630 & 3,8 & 4,1 & 3,9 & 4,5 & 3,8 & 3,1 & 2,3 & 2,6 \\
\hline & & 15 & 945 & 4,5 & 4,9 & 4,8 & 5,1 & 4,6 & 3,8 & 3,3 & 3,7 \\
\hline & & 20 & 1260 & 4,9 & 5,2 & 5,2 & 5,4 & 4,9 & 4,2 & 4,0 & 4,2 \\
\hline & \multirow{4}{*}{30} & 5 & 315 & 2,8 & 3,1 & 3,4 & 3,0 & 2,9 & 2,6 & 2,1 & 2,5 \\
\hline & & 10 & 630 & 4,1 & 4,5 & 4,8 & 4,2 & 4,2 & 4,2 & 3,7 & 4,0 \\
\hline & & 15 & 945 & 4,7 & 5,1 & 5,5 & 4,9 & 4,8 & 4,8 & 4,5 & 4,8 \\
\hline & & 20 & 1260 & 5,0 & 5,4 & 5,9 & 5,3 & 5,1 & 5,0 & 5,0 & 5,0 \\
\hline & \multirow{4}{*}{34} & 5 & 315 & 2,2 & 2,4 & 3,0 & 2,2 & 2,3 & 2,8 & 3,0 & 3,1 \\
\hline & & 10 & 630 & 3,5 & 3,8 & 4,3 & 3,5 & 3,6 & 4,0 & 4,6 & 4,4 \\
\hline & & 15 & 945 & 4,2 & 4,5 & 5,1 & 4,3 & 4,3 & 4,7 & 5,2 & 5,0 \\
\hline & & 20 & 1260 & 4,6 & 5,0 & 5,6 & 4,7 & 4,7 & 5,0 & 5,5 & 5,2 \\
\hline
\end{tabular}

138 Brito, A. C. de; Akutsu, M.; Salles, E. M.; Castro, G. M. 
Com os PCMs teóricos, obteve-se uma redução mais significativa, da ordem de $1,6{ }^{\circ} \mathrm{C}$ a $5,9{ }^{\circ} \mathrm{C}$, no valor da temperatura máxima diária. Esses resultados evidenciam a necessidade de uso de PCMs com maiores valores das temperaturas do ponto de fusão e da capacidade de armazenamento térmico latente para se obter melhorias no desempenho térmico de edificações brasileiras.

\section{Ponto de fusão}

Alterações no valor do ponto de fusão dos PCMs podem exercer papel significativo na resposta térmica do recinto (Figuras 10 a 13 e Tabela 8), para um mesmo valor da capacidade de armazenamento térmico latente. Com o uso de PCMs com a capacidade de armazenamento térmico latente original, nas cidades das zonas 1 a 5 , os PCMs com ponto de fusão de $30{ }^{\circ} \mathrm{C}$ proporcionaram menor amplitude diária e menor valor da temperatura máxima do ar interior, em comparação com as outras situações. Nos casos de ambientes expostos às condições climáticas de cidades nas zonas 6 a 8, situação correlata foi obtida com os PCMs com ponto de fusão de $34{ }^{\circ} \mathrm{C}$.

Esses resultados podem ser explicados analisandose os valores máximo e mínimo das temperaturas do ar no interior dos recintos, em relação ao valor do ponto de fusão dos PCMs. Nos modelos nas zonas bioclimáticas 1 a 5 , as temperaturas máximas diárias do ar interior estão entre $33,2^{\circ \mathrm{C}} \mathrm{e}$ $36,1{ }^{\circ} \mathrm{C}$, e as mínimas entre de $22,3{ }^{\circ} \mathrm{C}$ a $22,6{ }^{\circ} \mathrm{C}$. Nas zonas 6 a 8 , as temperaturas máximas diárias do ar interior variam de $37{ }^{\circ} \mathrm{C}$ a $39,6{ }^{\circ} \mathrm{C}$, e as temperaturas mínimas diárias variam de $24,8{ }^{\circ} \mathrm{C}$ a 26,6 ${ }^{\circ} \mathrm{C}$. Nessas situações, considerando-se os PCMs com ponto de fusão de $22{ }^{\circ} \mathrm{C}$, estes são acionados quando expostos a condições térmicas mais próximas das temperaturas mínimas diárias, não contribuindo de modo substancial para a redução da temperatura máxima do ar no ambiente. Para ter contribuições significativas dos PCMs no resfriamento dos ambientes, é necessário que seu ponto de fusão seja maior.

Autores como Peippo, Kauranen e Lund (1991) sugerem que o ponto de fusão ideal de um PCM seja da ordem de $1{ }^{\circ} \mathrm{C}$ a $3{ }^{\circ} \mathrm{C}$ acima do valor da temperatura média do ambiente sem esses materiais. Para verificar essa questão, na Tabela 9 são apresentados os valores do ponto de fusão ideal de PCMs recomendado pelos referidos autores e os valores dos pontos de fusão que proporcionaram melhores resultados no contexto do trabalho (menores valores da temperatura máxima do ar interior e menor amplitude diária), considerando-se PCMs com a capacidade de armazenamento térmico latente original. Observase que, de modo geral, os valores do ponto de fusão de PCMs, que se mostraram mais adequados ao desempenho térmico das edificações, estão compreendidos nos intervalos de valores dessa grandeza indicados por Peippo, Kauranen e Lund (1991).

Com os PCMs de capacidade teórica de armazenamento térmico latente o efeito do ponto de fusão no desempenho térmico dos modelos tende a ser menos significativo. Para um mesmo valor de capacidade de armazenamento térmico, nas zonas Z1 a Z5 resultados da mesma ordem de grandeza são obtidos com ponto de fusão entre 26 ${ }^{\circ} \mathrm{C}$ e $30{ }^{\circ} \mathrm{C}$, com resultados ligeiramente melhores para o ponto de fusão de $30{ }^{\circ} \mathrm{C}$. Nas zonas 6 a 8 situações correlatas ocorrem com ponto de fusão entre $30{ }^{\circ} \mathrm{C}$ e $34{ }^{\circ} \mathrm{C}$, com melhoria discreta nos resultados com o ponto de fusão de $34{ }^{\circ} \mathrm{C}$. Nesses casos, as recomendações de Peippo, Kauranen e Lund (1991), para a determinação do ponto de fusão ideal do material, passam a ser menos precisas.

Tabela 9 - Valores do ponto de fusão ideal dos PCMs com capacidade de armazenamento térmico latente original

\begin{tabular}{c|c|c|c}
\hline $\begin{array}{c}\text { Zona } \\
\text { bioclimática } \\
\text { brasileira }\end{array}$ & $\begin{array}{c}\text { Temperatura } \\
\text { média do ar } \\
\text { interior }\left({ }^{\mathbf{0}} \mathbf{C}\right)\end{array}$ & $\begin{array}{c}\text { Valor do ponto de } \\
\text { fusão “ideal” - } \\
\text { Peippo, Kauranen e } \\
\text { Lund (1991) }\left({ }^{\mathbf{0}} \mathbf{C}\right)\end{array}$ & $\begin{array}{c}\text { Valor do ponto de fusão das } \\
\text { situações analisadas com } \\
\text { melhores resultados }\left({ }^{\mathbf{0}} \mathbf{C}\right)\end{array}$ \\
\hline Z1 & 28,1 & 29,1 a 31,1 & \\
Z2 & 28,2 & 29,2 a 31,2 & 30 \\
Z3 & 29,3 & 30,3 a 32,3 & \\
Z4 & 26,8 & 27,8 a 29,8 & \\
Z5 & 28,5 & 29,5 a 31,5 & \\
\hline Z6 & 30,9 & 31,9 a 33,9 & \\
Z7 & 31,1 & 32,1 a 34,1 & \\
Z8 & 32,3 & 33,3 a 35,3 & \\
\hline
\end{tabular}




\section{Capacidade de armazenamento térmico}

Para um mesmo valor de ponto de fusão, aumentos substanciais no valor da capacidade de armazenamento térmico latente dos PCMs (de duas a quatro vezes o valor original) afetaram de modo significativo a resposta térmica dos recintos. Isso pode ser observado nos gráficos indicados nas Figuras 14 e 15, nos quais são apresentados os valores da temperatura máxima do ar interior em função da espessura da camada de PCMs com pontos de fusão de $22{ }^{\circ} \mathrm{C}$ a $34{ }^{\circ} \mathrm{C}$, respectivamente, para as zonas $1,5,6$ e 8 .

Observou-se ainda que há situações em que um maior valor da capacidade de armazenamento térmico latente pode até compensar um ponto de fusão menor do que aquele que seria mais adequado às condições climáticas do local. Isso pode ser observado no exemplo indicado na Figura 16. Na referida figura é apresentado um gráfico com indicação dos valores horários das temperaturas do ar exterior e no interior de recinto sem e com PCMs com ponto de fusão de $22{ }^{\circ} \mathrm{C}$, na zona bioclimática 3 , com vários valores de capacidade de armazenamento térmico latente. No exemplo verifica-se que nos modelos expostos às condições climáticas da zona 3 , em que o intervalo do ponto de fusão mais adequado é da ordem 30 ${ }^{\circ} \mathrm{C}$, a utilização de um PCM com ponto de fusão de $22{ }^{\circ} \mathrm{C}$, mas com maior valor de capacidade de armazenamento térmico latente, pode proporcionar uma redução significativa no valor da temperatura máxima do ar interior da ordem de $3{ }^{\circ} \mathrm{C}$, em comparação com recinto sem esses materiais.

\section{Desempenho térmico dos recintos}

Na Tabela 10 são indicados os valores máximos diários das temperaturas do ar no interior dos recintos sem PCMs e com PCMs, originais e teóricos, nas oito zonas bioclimáticas brasileiras, com a indicação do atendimento dos critérios referentes ao nível mínimo de desempenho térmico de edificações conforme a norma NBR 15575 (ABNT, 2013).

Figura 14 - Gráficos da temperatura máxima do ar interior em modelo com sistema leve, com PCMs em várias espessuras e ponto de fusão de $22{ }^{\circ} \mathrm{C}$ a $34^{\circ} \mathrm{C}$, nas zonas 1 e 5
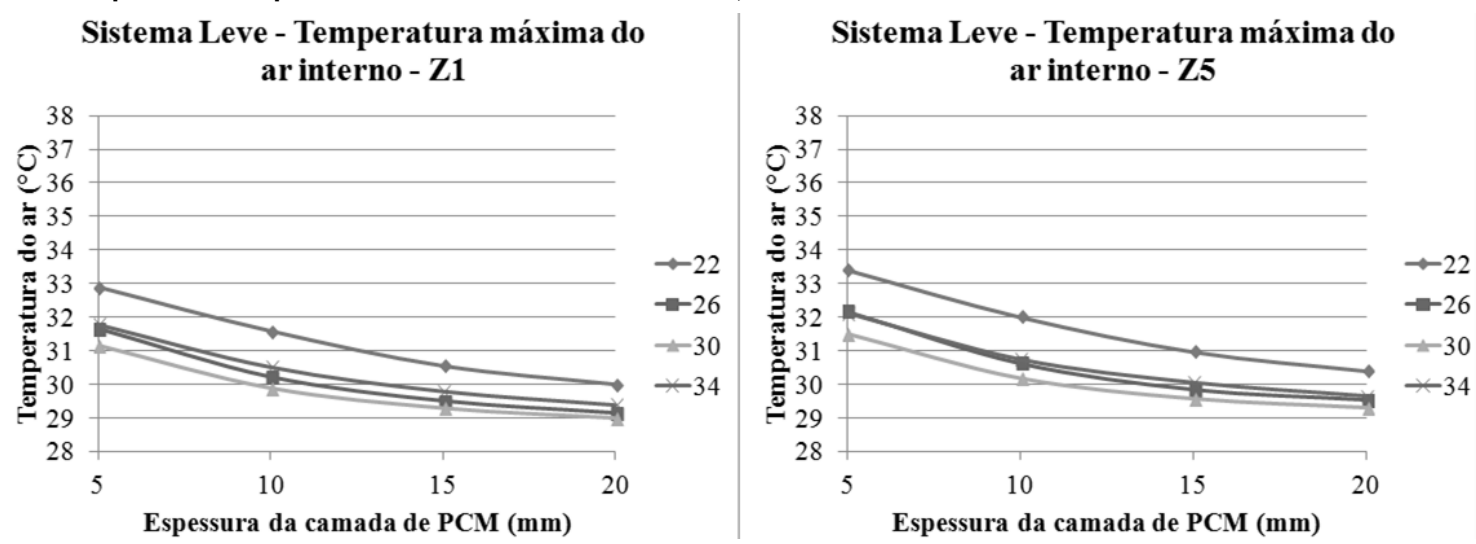

Figura 15 - Gráficos da temperatura máxima do ar interior em modelo com sistema leve, com PCMs em várias espessuras e ponto de fusão de $22^{\circ} \mathrm{C}$ a $34^{\circ} \mathrm{C}$, nas zonas 6 a 8

Sistema Leve - Temperatura máxima do ar interno - Z6

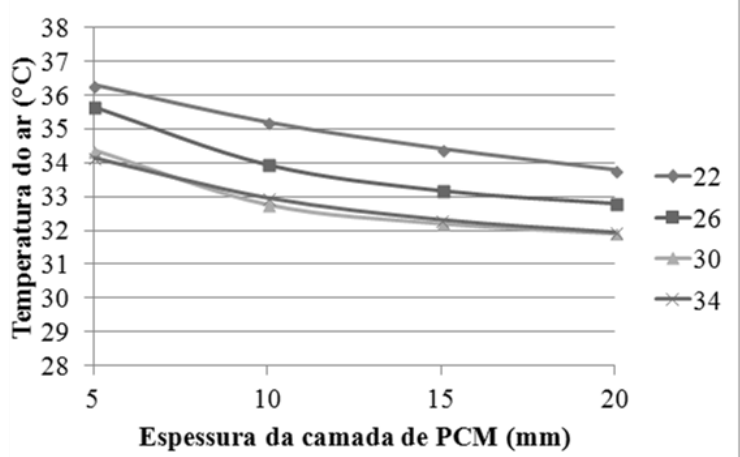

Sistema Leve - Temperatura máxima do ar interno - $\mathbf{Z 8}$

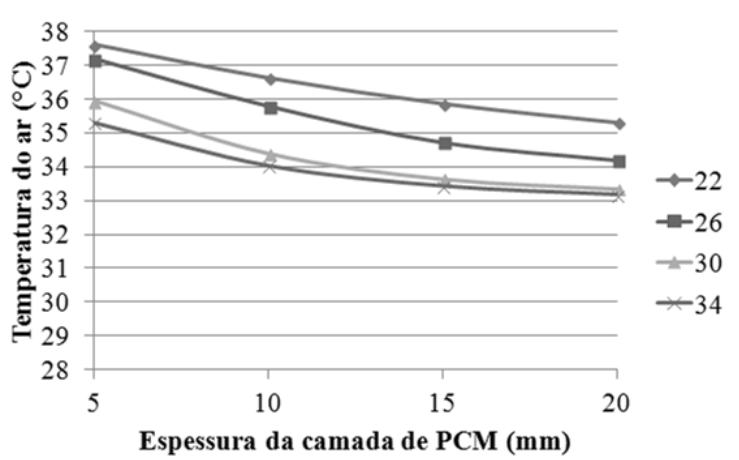

140 Brito, A. C. de; Akutsu, M.; Salles, E. M.; Castro, G. M. 
Figura 16 - Gráfico da temperatura do ar interior em modelo com sistema leve, sem PCMs e com PCMs com ponto de fusão de $22^{\circ} \mathrm{C}$

\section{$\mathrm{Z3}$ - Sistema Leve - PCM c/ Ponto de fusão $22^{\circ} \mathrm{C}$}

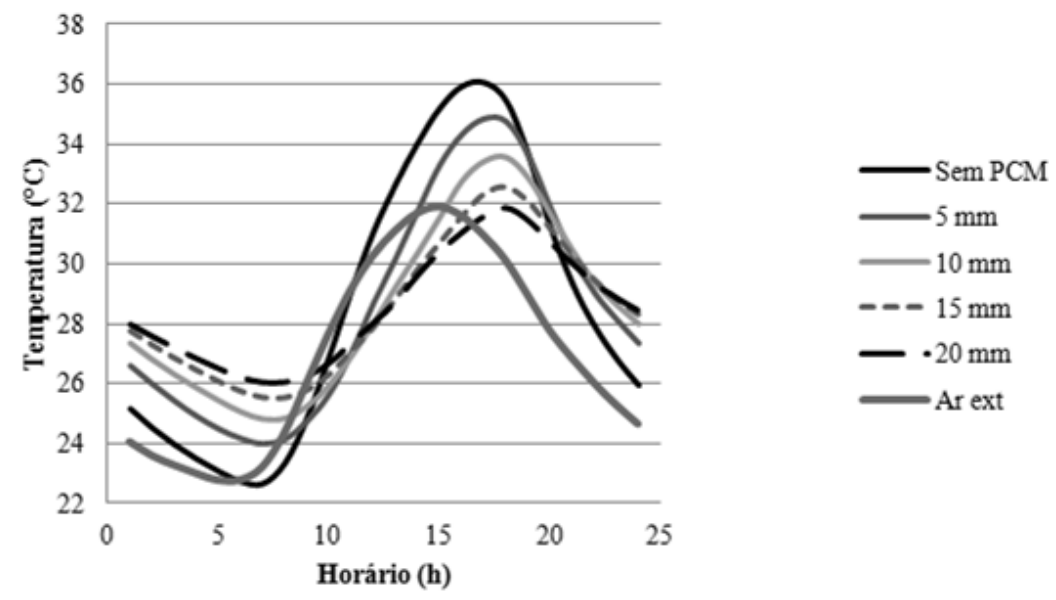

Tabela 10 - Valores da temperatura máxima diária no exterior e no interior de recintos sem PCMs e com PCMs em suas características originais e PCMs teóricos expostos às condições climáticas das oito zonas bioclimáticas brasileiras

\begin{tabular}{|c|c|c|c|c|c|c|c|c|c|c|}
\hline & $\begin{array}{c}\text { Ponto de } \\
\text { fusão }\left({ }^{\circ} \mathrm{C}\right)\end{array}$ & $\begin{array}{c}\text { Espessura } \\
(\mathrm{mm})\end{array}$ & Z1 & $\mathbf{Z 2}$ & $\mathbf{Z 3}$ & $\mathbf{Z 4}$ & $\mathbf{Z 5}$ & Z6 & $\mathbf{Z 7}$ & Z8 \\
\hline PCMs originais & 22 & 5 & 32,9 & 33,3 & 34,8 & 31,6 & 33,4 & 36,3 & 39,0 & 37,6 \\
\hline \multirow{15}{*}{ PCMs teóricos } & \multirow{3}{*}{22} & 10 & 31,6 & 31,9 & 33,6 & 29,9 & 32,0 & 35,2 & 38,0 & 36,6 \\
\hline & & 15 & 30,6 & 30,8 & 32,6 & 29,1 & 31,0 & 34,4 & 37,2 & 35,9 \\
\hline & & 20 & 30,0 & 30,2 & 31,9 & 28,7 & 30,4 & 33,8 & 36,7 & 35,3 \\
\hline & \multirow{4}{*}{26} & 5 & 31,8 & 32,0 & 33,7 & 30,4 & 32,2 & 35,7 & 38,7 & 37,2 \\
\hline & & 10 & 30,2 & 30,5 & 32,1 & 28,8 & 30,6 & 33,9 & 37,4 & 35,8 \\
\hline & & 15 & 29,5 & 29,6 & 31,3 & 28,1 & 29,8 & 33,2 & 36,4 & 34,7 \\
\hline & & 20 & 29,0 & 29,3 & 30,8 & 27,8 & 29,5 & 32,8 & 35,6 & 34,2 \\
\hline & \multirow{4}{*}{30} & 5 & 31,2 & 31,4 & 32,7 & 30,2 & 31,5 & 34,4 & 37,5 & 35,9 \\
\hline & & 10 & 29,9 & 30,1 & 31,2 & 29,0 & 30,2 & 32,8 & 35,9 & 34,4 \\
\hline & & 15 & 29,3 & 29,4 & 30,6 & 28,4 & 29,6 & 32,2 & 35,1 & 33,6 \\
\hline & & 20 & 29,0 & 29,0 & 30,2 & 27,9 & 29,3 & 31,9 & 34,7 & 33,3 \\
\hline & \multirow{4}{*}{34} & 5 & 31,8 & 32,1 & 33,0 & 31,0 & 32,1 & 34,2 & 36,6 & 35,3 \\
\hline & & 10 & 30,5 & 30,7 & 31,8 & 29,7 & 30,7 & 33,0 & 35,1 & 34,0 \\
\hline & & 15 & 29,8 & 30,0 & 31,0 & 29,0 & 30,1 & 32,3 & 34,4 & 33,4 \\
\hline & & 20 & 29,4 & 29,5 & 30,5 & 28,5 & 29,7 & 32,0 & 34,2 & 33,2 \\
\hline \multicolumn{3}{|c|}{ Sem PCMs } & 34,0 & 34,5 & 36,1 & 33,2 & 34,4 & 37,0 & 39,6 & 38,4 \\
\hline \multicolumn{3}{|c|}{ Temp. máx. ar ext. $\left({ }^{\circ} \mathrm{C}\right)$} & 31,4 & 31,8 & 31,9 & 31,2 & 31,7 & 33,6 & 37,8 & 34,9 \\
\hline
\end{tabular}

Nota: células não hachuradas indicam o atendimento do critério mínimo de desempenho térmico segundo a norma NBR 15575 (ABNT, 2013). Células hachuradas indicam o não atendimento do critério mínimo de desempenho térmico.

Observou-se que em todas as zonas bioclimáticas brasileiras os recintos sem PCMs ou com PCMs em suas características originais não atendem o critério referente ao nível mínimo de desempenho térmico de acordo com a norma NBR 15575 (ABNT, 2013). Entretanto, com o uso de PCMs teóricos, dependendo do valor de capacidade de armazenamento térmico latente e do ponto de fusão, há situações nas quais são atendidos os critérios referentes ao nível mínimo de desempenho térmico, especialmente com o uso de PCMs com maior capacidade de armazenamento térmico latente, obtida com $20 \mathrm{~mm}$ de espessura do painel de PCMs e maior valor do ponto de fusão, em comparação com os PCMs originais. 
Inércia térmica, conforto térmico e o clima do local

O acréscimo de PCMs nos modelos proporciona um aumento substancial na inércia térmica dos ambientes, o que contribui para a redução da amplitude diária e do valor da temperatura máxima do ar interior, resultando no atendimento do critério referente ao nível mínimo de desempenho térmico segundo a norma NBR 15575 (ABNT, 2013) em várias situações, como apresentado na Tabela 10. Por outro lado, o uso de tais materiais também acarreta um aumento no valor da temperatura mínima do ar interior do recinto, fator que não é abordado nos critérios de avaliação da referida norma. Entretanto, dependendo do clima do local, esse comportamento pode piorar a sensação de conforto térmico do usuário.
De modo geral, nas zonas bioclimáticas 1 a 5, nos modelos com PCMs há uma melhoria da sensação de conforto térmico do usuário, visto que os valores da temperatura máxima e mínima diária do ar interior ficam mais próximos ou dentro do intervalo de valores da zona de conforto térmico. Entretanto, o mesmo não acontece nas demais zonas, que apresentam condições de verão mais extremas. Nas zonas bioclimáticas 6 a 8, como a temperatura mínima diária do ar interior tende a ser maior do que os valores estabelecidos na faixa de conforto térmico, o acréscimo de PCMs nos ambientes ocasiona um maior período de desconforto do usuário. Nas Figuras 17 e 18 são apresentados gráficos com exemplos dessas situações, indicando-se os valores horários da temperatura do ar exterior e no interior de recintos sem e com PCMs, respectivamente, nas zonas bioclimáticas 3 e 8 .

Figura 17 - Gráfico da temperatura do ar interior em modelo com sistema leve com PCMs em placa de $20 \mathrm{~mm}$ de espessura e ponto de fusão de $30^{\circ} \mathrm{C}$, na zona 3

\section{$\mathrm{Z3}$ - Sistema Leve - PCM c/ Ponto de fusão $30^{\circ} \mathrm{C}$}

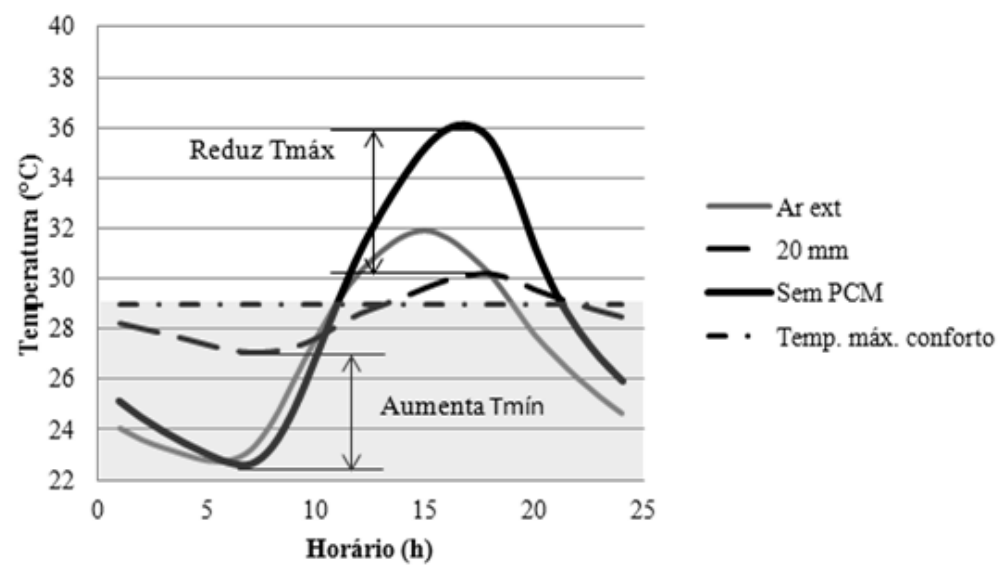

Figura 18 - Gráfico da temperatura do ar interior em modelo com sistema leve com PCMs em placa de $20 \mathrm{~mm}$ de espessura e ponto de fusão de $34^{\circ} \mathrm{C}$, na zona 8

Z8 - Sistema Leve - PCM c/ Ponto de fusão $34^{\circ} \mathrm{C}$

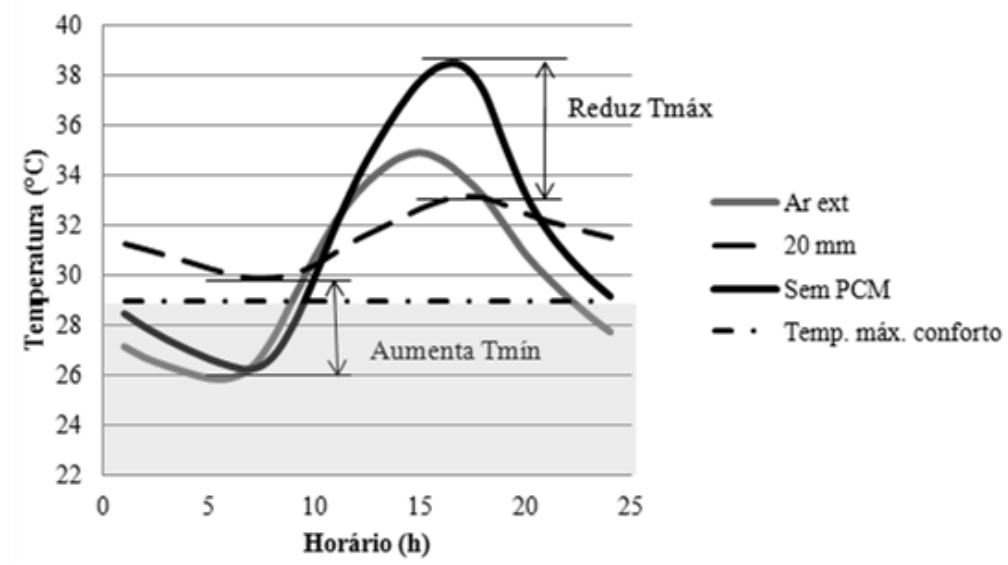

142 Brito, A. C. de; Akutsu, M.; Salles, E. M.; Castro, G. M. 


\section{Conclusões}

Os PCMs são mais promissores para proporcionar a melhoria do desempenho térmico de recintos com sistemas construtivos leves que, em sua configuração inicial, apresentam baixa inércia térmica, expostos às condições climáticas de locais nos quais a inércia térmica seja requerida como estratégia passiva de climatização.

Os PCMs originais, com ponto de fusão de $22 \mathrm{oC}$ e capacidade de armazenamento térmico latente de $315 \mathrm{~kJ} / \mathrm{m}^{2}$, propiciam melhorias menos significativas no desempenho térmico dos recintos em cidades nas oito zonas bioclimáticas brasileiras. Isso evidencia a necessidade de desenvolver materiais cujas características térmicas sejam mais apropriadas ao clima desses locais.

Sob tal aspecto, nas zonas bioclimáticas 1 a 5 PCMs com ponto de fusão da ordem de 30 oC proporcionam melhor desempenho térmico dos modelos. Nas zonas 6 a 8 melhores resultados são obtidos com ponto de fusão da ordem de 34 oC. Entretanto, é fundamental analisar a resposta térmica da edificação, previamente sem esses materiais, para se ter informações sobre o custo benefício de sua aplicação. Nas zonas 6 a 8, em especial, esses materiais precisam ser usados com maior ponderação, pois a inércia térmica adicional dos ambientes, proporcionada pelos PCMs, pode piorar as condições de conforto térmico do usuário.

Com relação à capacidade de armazenamento térmico latente, é desejável que os PCMs tenham um valor maior que $315 \mathrm{~kJ} / \mathrm{m}^{2}$, especialmente nas zonas bioclimáticas 1 a 5 , nas quais recintos com maior inércia térmica tem maior potencial em proporcionar conforto térmico dos usuários. Tal aspecto é ainda mais importante do que o ponto de fusão, pois, dependendo da situação, um maior valor de capacidade de armazenamento térmico latente pode compensar um ponto de fusão menos adequado.

Como não foram considerados todos os fatores que interferem na resposta térmica de edificações, tais como alterações na sua forma, nas dimensões, nas proporções de materiais transparentes e opacos, nas condições de sombreamento e orientações de aberturas envidraçadas e na taxa de ventilação dos recintos, isso precisa ser considerado ao efetuarem-se generalizações dos resultados obtidos.

O ponto de fusão e a capacidade de armazenamento térmico latente de PCMs, que são apontados neste estudo, servem como uma referência inicial para a seleção ou para o desenvolvimento de materiais com características térmicas potencialmente mais apropriadas ao clima de localidades brasileiras. Fornecem ainda embasamento técnico para a realização de mais estudos e testes do desempenho térmico de protótipos brasileiros reais com PCMs, fatores que também serão abordados na continuidade do projeto de pesquisa da qual esta publicação faz parte.

\section{Referências}

AHMAD, M. et al. Thermal Testing and Numerical Simulation of a Prototype Cell Using light Wallboards Coupling Vacuum Isolation Panels and Phase Change Material. Energy and Buildings, v. 38, n. 6, p. 673-681, jun. 2006.

AKUTSU, M. Método Para Avaliação do Desempenho Térmico de Edificações no Brasil. São Paulo, 1998. 150 f. Tese (Doutorado em Engenharia Civil) - Faculdade de Arquitetura e Urbanismo, Universidade de São Paulo, São Paulo, 1998.

\section{AMERICAN SOCIETY OF HEATING, REFRIGERATING AND AIR-CONDITIONING} ENGINEERS. Standard 55: thermal environmental conditions for human occupancy. Atlanta, 2013.

ASSOCIAÇÃO BRASILEIRA DE NORMAS TÉCNICAS. NBR 15220: desempenho térmico de edificações. Rio de Janeiro, 2008.

ASSOCIAÇÃO BRASILEIRA DE NORMAS TÉCNICAS. NBR 15575: edifícios habitacionais: desempenho. Rio de Janeiro, 2013.

ATHIENITIS, A. K. et al. Investigation of the Thermal Performance of a Passive Solar TestRoom With Wall Latent Heat Storage. Building and Environment, v. 32, n. 5, p. 405-410, set. 1997.

BAETENS, R.; JELLE, B. P.; GUSTAVSEN, A. Phase Change Materials For Building Applications: a state-of-the-art review. Energy and Buildings, v. 42, n. 9, p. 1361-1368, set. 2010.

BRITO, A. et al. Análise da Resposta do Programa Energy Plus Para Simulação do Comportamento Térmico de Recinto Com Materiais de Mudança de Fase. In: ENCONTRO NACIONAL DE CONFORTO NO AMBIENTE CONSTRUIDO, 13., Campinas, 2015. Anais... Campinas: ANTAC, 2015.

CABEZA, L. F. et al. Use of Microencapsulated PCM in Concrete Walls for Energy Savings.

Energy and Buildings, v. 39, n. 2, p. 113-119, fev. 2007. 
CAO, S.; GUSTAVSEN, A.; UVSLØKK, S. The Effect of Wall-Integrated Phase Change Material Panels on the Indoor Air and Wall Temperature Hot box Experiments. In: Renewable Energy Conference 2010. Proceedings... Trondheim, Norway: 15-26.

CHAN, A. L. S. Energy and Environmental Performance of Building Façades Integrated With Phase Change Material in Subtropical Hong Kong. Energy and Buildings, v. 43, n. 10, p. 2947-2955, out. 2011.

FARID, M. M. et al. A Review on Phase Change Energy Storage: materials and applications.

Energy Conversion and Management, v. 45, n. 9-10, p. 1597-1615, jun. 2004.

GUYER, E. C. Handbook of Applied Thermal Design. London: [s.n.], 1999.

KUZNIK, F.; VIRGONE, J. Experimental Assessment of a Phase Change Material for w|All Building Use. Applied Energy, v. 86, n. 10, p. 2038-2046, out. 2009.

KUZNIK, F.; VIRGONE, J.; ROUX, J.-J. Energetic Efficiency of Room Wall Containing PCM Wallboard: a full-scale experimental investigation. Energy and Buildings, v. 40, n. 2, p. 148-156, jan. 2008.

MEHLING, H.; CABEZA, L. F. Heat and Cold storage With PCM : an up to date introduction into basics and applications. Berlin: Springer, 2008.

PASUPATHY, A.; VELRAJ, R. Effect of Double Layer Phase Change Material in Building Roof for Year Round Thermal Management. Energy and Buildings, v. 40, n. 3, p. 193-203, jan. 2008.

PEIPPO, K.; KAURANEN, P.; LUND, P. D. A Multicomponent PCM Wall Optimized For Passive Solar Heating. Energy and Buildings, v. 17, p. 259-270, 1991.
SHARMA, A. et al. Review on Thermal Energy Storage With Phase Change Materials and Applications. Renewable and Sustainable Energy Reviews, v. 13, n. 2, p. 318-345, fev. 2009.

TABARES-VELASCO, P. C. et al. Verification and Validation of EnergyPlus Phase Change Material Model For Opaque Wall Assemblies. Building and Environment, v. 54, p. 186-196, ago. 2012.

\section{UNITED STATES DEPARTMENT OF \\ ENERGY. Energy Plus Simulation Software, 2015.}

VOELKER, C.; KORNADT, O.; OSTRY, M. Temperature Reduction Due to the Application of Phase Change Materials. Energy and Buildings, v. 40, n. 5, p. 937-944, jan. 2008.

ZHANG, M.; MEDINA, M. A.; KING, J. B. Development of a Thermally Enhanced Frame Wall With Phase-Change Materials For on-Peak Air Conditioning Demand Reduction and Energy Savings in Residential Buildings. International Journal of Energy Research, v. 29, n. 9, p. 795809, jul. 2005.

\section{Agradecimentos}

Os autores agradecem ao Instituto de Pesquisas Tecnológicas do Estado de São Paulo (IPT) pelo financiamento da primeira fase do projeto interno de pesquisa intitulado "Materiais de mudança de fase: potencial de uso em edificações brasileiras", da qual esta publicação é parte integrante. Agradecem também ao Dr. Fulvio Vittorino, diretor do Centro Tecnológico do Ambiente Construído (CETAC/IPT) pelo inestimável apoio técnico ao trabalho. 
Adriana Camargo de Brito

Laboratório de Conforto Ambiental e Sustentabilidade, Centro de Tecnologia do Ambiente Construído | Instituto de Pesquisas Tecnológicas do Estado de São Paulo | Av. Prof. Almeida Prado, 532, Cidade Universitária | São Paulo - SP - Brasil | CEP 05508-901 | Tel.: (11) 3767-4579 | E-mail: adrianab@ipt.br

Maria Akutsu

Laboratório de Conforto Ambiental e Sustentabilidade, Centro de Tecnologia do Ambiente Construído | Instituto de Pesquisas Tecnológicas do Estado de São Paulo | Tel.: (11) 3767-4258 | E-mail: akutsuma@ipt.br

Elisa Morande Salles

Laboratório de Conforto Ambiental e Sustentabilidade, Centro de Tecnologia do Ambiente Construído | Instituto de Pesquisas Tecnológicas do Estado de São Paulo | Tel.: (11) 3767-4579 | E-mail: elisams@ipt.br

\section{Guilherme Molnar Castro}

Departamento de Física Aplicada, Instituto de Física | Universidade de São Paulo | Rua do Matão, 1371, Butantã | São Paulo - SP - Brasil | CEP 05508-090 | Tel.: (11) 3091-6861 | E-mail: gmolnar@ipt.br

\section{Revista Ambiente Construído}

Associação Nacional de Tecnologia do Ambiente Construído

Av. Osvaldo Aranha, $99-3^{\circ}$ andar, Centro

Porto Alegre - RS - Brasil

CEP $90035-190$

Telefone: +55 (51) 3308-4084

Fax: +55 (51) 3308-4054

www.seer.ufrgs.br/ambienteconstruido

E-mail: ambienteconstruido@ufrgs.br 